\title{
Dominant patterns of winter-time intraseasonal surface air temperature over the CONUS in response to MJO convections
}

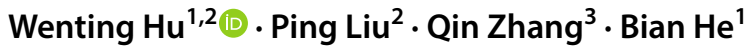

Received: 13 June 2018 / Accepted: 5 April 2019 / Published online: 12 April 2019

(c) The Author(s) 2019

\begin{abstract}
The dominant patterns of the intraseasonal surface air temperature (SAT) over the Contiguous United States (CONUS) during wintertime (December-March) are investigated in the period of 1979-2014 in the present study. The first two leading modes revealed by the empirical orthogonal function (EOF) analysis sufficiently represent the patterns by explaining nearly $80 \%$ of the total variance. The EOF1 mode has a monopole pattern with large loadings in the central-north CONUS, while the EOF2 has a dipole pattern with loadings of opposing signs in the northwestern and southeastern CONUS. The monopole pattern of the EOF1 has a significant lead-lag correlation with the EOF2 dipole pattern. These dominant patterns are traced back to the convective anomalies of the Madden-Julian Oscillation (MJO) which has eight phases characterized by the revised real-time multivariate $\mathrm{MJO}$ index. The connections are established dynamically by Rossby wave trains propagating from the MJO convections to North America. Specifically, the monopole warming (EOF1) is well developed by lagging about two pentads from enhanced MJO convections during phase 4 over the Maritime Continent as the wave sources. The dipole pattern (EOF2) of "warm-West/cool-East" starts to develop during MJO phase 7 with enhanced convections over the Western Pacific and reaches a maximum about two pentads later. Such dynamic lead-lag relationships on intraseasonal time scales are revealed by both diagnostic analysis and numerical experiments using a linear baroclinic model, which are potentially useful for predicting intraseasonal variations in SAT over the CONUS.
\end{abstract}

Keywords $\mathrm{MJO} \cdot \mathrm{CONUS}$ surface temperature $\cdot$ Intraseasonal variations $\cdot$ Wintertime

\section{Introduction}

Subseasonal ( 5-120 days) variations of surface air temperature (SAT) is closely related to warm and cold events over the Contiguous United States (CONUS) in wintertime (December-March; DFJM) to impact economy, water resources and society. Understanding the subseasonal variability of the CONUS SAT and its causes potentially

Wenting $\mathrm{Hu}$

hwt@lasg.iap.ac.cn

1 State Key Laboratory of Numerical Modeling for Atmospheric Sciences and Geophysical Fluid Dynamics, Institute of Atmospheric Physics, Chinese Academy of Sciences, Beijing 100029, China

2 School of Marine and Atmospheric Sciences, Stony Brook University, Stony Brook, NY, USA

3 Climate Prediction Center, NCEP/NWS/NOAA, College Park, MD, USA improves the intraseasonal ( $20-100$ days) predictions to reduce damages.

The subseasonal variations of CONUS SAT are associated with the Madden-Julian Oscillation (MJO), the most dominant mode of intraseasonal variability in the tropics (Madden and Julian 1972). In general MJO heating forces Rossby wave trains propagating to the extratropics to induce atmospheric circulation anomalies in the middle latitudes (Higgins and Shi 2001; Vecchi and Bond 2004; Matthews et al. 2004; Seo and Son 2012; Yoo et al. 2012; Seo et al. 2016; Seo and Lee 2017; Lukens et al. 2017). The circulation anomalies more directly modulate the SAT anomalies in the middle latitudes as a delayed response to the tropical MJO forcing with a time lag of 1-3 weeks (Higgins et al. 2000; Lin and Brunet 2009; Schreck III et al. 2013; Riddle et al. 2013; Rodney et al. 2013; Matsueda and Takaya 2015; Seo et al. 2016). For example, enhanced convection in MJO phase 3 induces adiabatic subsidence for warming anomalies in East Asia, whereas the enhanced MJO convection over the Indian Ocean and suppressed MJO convection over the 
Western Pacific trigger Rossby waves at zonal wavenumbers 2-4 to impact SAT variations over North America and Eastern Europe (Seo et al. 2016).

A stronger and more active MJO is more influential on the extratropics during northern winters (Hendon et al. 2000; Rodney et al. 2013). Strong MJO convection generates and amplifies extratropical Rossby waves and modulates teleconnections such as the Pacific-North American (PNA) pattern (Mori and Watanabe 2008), which is known to influence the intraseasonal variability of winter-time SAT over the CONUS (Schreck III et al. 2013). Statistically the subseasonal SAT variability over North America covering $10^{\circ}-70^{\circ} \mathrm{N}, 150^{\circ}-40^{\circ} \mathrm{W}$ was diagnosed to connect with the MJO and the PNA pattern in the leading modes (Lin 2015). This variability has notable peaks on intraseasonal time scales (Fig. 3 of Lin 2015). A recent power spectral analysis (Yang and Li 2016) also indicates that the subseasonal SAT in the middle latitudes has peaks at 20-80 days close to or above the $99 \%$ significance level (their Fig. 1). Once the impacting pathway is established, a simultaneous-like linkage can also be formed between the MJO and the SAT over the CONUS (Zhou et al. 2012). Specifically when enhanced convection occurs over the equatorial Indian Ocean, a negative SAT anomaly tends to develop over New England and the Great Lakes. As strong MJO convection shifts eastward to the Maritime Continent, a positive SAT anomaly develops in the eastern US from Maine to Florida.

There are some limitations in previous studies on how MJO influences the winter-time SAT over the CONUS. Firstly, the simultaneous-like relationship between the MJO and the SAT can be established in statistics (e.g., Zhou et al. 2012), while a delayed response should actually be in play. Secondly, the SAT variability at the shorter end (5-20 days) of subseasonal variations may be controlled by mid-latitude atmospheric thermos-dynamics such as planetary waves and baroclinic instability more than the remote MJO convections. This less-important relationship with the MJO was disclosed before (e.g., Lin 2015) and can be elucidated by nearly a null correlation (not shown). Thirdly, the statistical relationships should be further verified by numerical experiments based on either theoretical models or eventually operational forecast systems. The limitations motivate our present study to focus on the relationship between the intraseasonal (20-100 days) variations of the CONUS SAT and MJO convections. We will demonstrate that the intraseasonal component of the CONUS SAT is more closely connected with the MJO and the connection is established through the dominant patterns of the SAT and a lagged relationship with the MJO. The dominant patterns will be derived by empirical orthogonal function (EOF) analysis and their evolution will be connected with the intraseasonal atmospheric circulations. MJO convections as Rossby wave sources contribute to the circulations through Rossby wave dispersion and then to the dominant intraseasonal SAT patterns. The Rossby waves as a response to the MJO convections will be finally verified by numerical experiments based on a linear baroclinic model.

In the remainder of the paper, the datasets, methods and model used in this study are introduced in Sect. 2. In Sect. 3, the dominant patterns of the winter-time intraseasonal SAT over the CONUS and the thermodynamic processes responsible for the generation of the SAT anomaly are analyzed. In Sect. 4, the impact of MJO convection on the dominant patterns is established by both diagnostic analysis and numerical experiments using a linear baroclinic model. Summaries and discussions are presented in Sect. 5.

\section{Datasets, methods and model}

\subsection{Datasets}

Observed daily SAT data at a high spatial resolution $\left(1 / 16^{\circ}\right)$ (Livneh et al. 2015) were gridded from approximately 20,000 National Climatic Data Center (NCDC) stations across the CONUS from http://www.colorado.edu/lab/livneh/data and are further interpolated to $1^{\circ} \times 1^{\circ}$ longitude by latitude in this study. Daily outgoing longwave radiation (OLR; Liebmann and Smith 1996) from 1979-2014 was obtained from the National Oceanic and Atmospheric Administration (NOAA) as a proxy of tropical convection. Daily mean winds at 850 , 500 and $200 \mathrm{hPa}$, isobaric vertical velocity and the geopotential height at $500 \mathrm{hPa}$ are derived from the National Centers for Environmental Prediction (NCEP)-US Department of Energy (DOE) Reanalysis II Project (Kanamitsu et al. 2002) to establish connections between the MJO and the CONUS SAT. The OLR and dynamic fields have a spatial resolution of $2.5^{\circ} \times 2.5^{\circ}$ and cover 34 winter seasons (December-March; DJFM) between 1979/1980 and 2013/2014.

\subsection{Methods}

The subseasonal component of the SAT over the CONUS is obtained through a band-pass filter (Duchon 1979) at 5-120 days to the raw daily anomalies. The intraseasonal component is derived by applying the same bandpass filter at 20-100 days, since the period of 20-100 days corresponds to typical time scales of the MJO (Waliser et al. 2009). The subset in the DJFM seasons is used for analysis. Because the dominant patterns of the 5-20-day filtered SAT do not have a significant relationship with MJO convection in terms of Rossby wave fluxes (not shown), the present study focuses on the characteristics of the 20-100-day filtered SAT and their relationships with $\mathrm{MJO}$ activities.

An EOF analysis is then applied to derive the dominant patterns of the intraseasonal SAT over the CONUS during winter 
time. The SAT and atmospheric circulation evolutions associated with the principal components (PCs) are analyzed with lagged composites. The auto-correlation of the $\mathrm{PC}$ time series is the basis for calculating the effective degree of freedom.

The perturbed thermodynamic equation at $1000 \mathrm{hPa}$ of Seo et al. (2016) is adopted and cited below to compare the relevant physical and dynamic processes in generating the dominant SAT patterns.

$$
\begin{aligned}
\frac{\partial\{T\}}{\partial t}= & -\vec{V}_{H} \cdot \nabla_{H}\{T\}-\left\{\vec{V}_{H}\right\} \cdot \nabla_{H} \bar{T}-\left\{\vec{V}_{H}^{\prime} \cdot \nabla_{H} T^{\prime}\right\} \\
& +\left(\frac{R}{C_{p}} \frac{\{T\}}{P}-\frac{\partial\{T\}}{\partial p}\right) \bar{\omega}+\left(\frac{R}{C_{p}} \frac{\bar{T}}{P}-\frac{\partial \bar{T}}{\partial p}\right)\{\omega\} \\
& +\left(\left\{\frac{R}{C_{p}} \frac{T^{\prime}}{P} \omega^{\prime}\right\}-\left\{\frac{\partial T^{\prime}}{\partial p} \omega^{\prime}\right\}\right)+\{Q 1\}+\{R E S\},
\end{aligned}
$$

where the overbar denotes the DJFM mean and the prime for the total anomaly. The curly brackets represent the anomalies at intraseasonal time scales. $\vec{V}_{H}$ is the horizontal wind, and $\omega$ is the vertical velocity in the pressure coordinates. $R$ is the gas constant for dry air, and $C_{p}$ is the specific heat of the dry air at a constant pressure. The left-hand term in Eq. (1) is the 20-100-day filtered temperature $(\{T\})$ tendency. The first three terms on the right-hand side are associated with the horizontal advections of (1) intraseasonal temperature by mean winds, (2) mean temperature by intraseasonal winds, and (3) intraseasonal temperature by intraseasonal winds. The subsequent three terms are the adiabatic heating created in the interaction between (1) intraseasonal temperature and mean vertical velocity, (2) mean temperature and intraseasonal vertical velocity, and (3) the two intraseasonal anomalies. The seventh term represents the intraseasonal component of the diabatic heating estimated from the apparent heat source (Yanai et al. 1973). The residual term $\{R E S\}$ is small and neglected.

The phase-independent wave activity flux $\mathbf{W}$ (Takaya and Nakamura 2001) is computed to dynamically connect the SAT evolution with the MJO convection. Compared with the method of Plumb (1985), this wave activity flux $\mathbf{W}$ is derived without any time average and depicts instantaneous three-dimensional wave-packet propagations.

In spherical coordinates, $\mathbf{W}$ is expressed as follows: where $(U, V)$ are the zonal and meridional components of basic flows; $(\lambda, \phi)$ are longitude and latitude; $a$ is the Earth's radius; $f_{0}=2 \Omega \sin \phi$ is the Coriolis parameter; $N^{2}$ is the buoyancy frequency; $p$ is the pressure scaled by $1000 \mathrm{hPa}$, and $\mathbf{C}_{U}$ represents the phase propagation vector in the direction of $\mathbf{U}(U, V)$. The three-dimensional perturbation of stream functions is denoted by $\{\psi\}$.

The wave activity (angular) pseudo-momentum $M$ is defined as

$M=\frac{p}{2}\left(\frac{\{q\}^{2}}{2\left|\nabla_{H} Q\right|}+\frac{e}{|\mathbf{U}|-c_{p}}\right) \cos \phi$,

where

$\{q\}=\frac{\partial^{2}\{\psi\}}{\partial x^{2}}+\frac{\partial^{2}\{\psi\}}{\partial y^{2}}+\frac{f_{0}^{2}}{p} \frac{\partial}{\partial z}\left(\frac{p}{N^{2}} \frac{\partial\{\psi\}}{\partial z}\right)$

and $Q$ is the potential vorticity of the wave and basic flow; $\nabla_{H}$ is a horizontal Hamiltonian operator; $c_{p}$ is the phase speed of the migratory perturbations in the direction of basic flow $\mathbf{U}$; and

$e=\frac{1}{2}\left[\left(\frac{\partial\{\psi\}}{\partial x}\right)^{2}+\left(\frac{\partial\{\psi\}}{\partial y}\right)^{2}+\left(\frac{f_{0}}{N} \frac{\partial\{\psi\}}{\partial z}\right)^{2}\right]$

is the wave energy.

In the present study, the horizontal components of the wave activity flux $\mathbf{W}$ at $200 \mathrm{hPa}$ represent the quasi-barotropic Rossby waves propagating from the tropics to North America. The perturbed variables such as the potential vorticity and the wave energy are derived from the lagged composite difference of 20-100-day filtered stream functions at $200 \mathrm{hPa}$ (cf. Eqs. 4 and 5). The phase speed of the migratory perturbations $c_{p}$ is estimated at each grid point using the following procedure. First, the days when the absolute values of PCs are greater than one standard deviation and correspondingly lagging day between -15 and -1 are selected as the reference. Then, the lead-lag spatial correlation coefficients of 20-100-day-filtered 250-hPa geopotential height time series over the 23-day period centered on the reference days are calculated, with a time lag of 1 day. The maximum positive correlation center on the lead-lag correlation maps

$$
\mathbf{W}=\frac{p \cos \phi}{2|\mathbf{U}|}\left(\begin{array}{l}
\frac{U}{a^{2} \cos ^{2} \phi}\left[\left(\frac{\partial\{\psi\}}{\partial \lambda}\right)^{2}-\{\psi\} \frac{\partial^{2}\{\psi\}}{\partial \lambda^{2}}\right]+\frac{V}{a^{2} \cos \phi}\left[\frac{\partial\{\psi\}}{\partial \lambda} \frac{\partial\{\psi\}}{\partial \phi}-\{\psi\} \frac{\partial^{2}\{\psi\}}{\partial \lambda \partial \phi}\right] \\
\frac{U}{a^{2} \cos \phi}\left[\frac{\partial\{\psi\}}{\partial \lambda} \frac{\partial\{\psi\}}{\partial \phi}-\{\psi\} \frac{\partial^{2}\{\psi\}}{\partial \lambda \partial \phi}\right]+\frac{V}{a^{2}}\left[\left(\frac{\partial\{\psi\}}{\partial \phi}\right)^{2}-\{\psi\} \frac{\partial^{2}\{\psi\}}{\partial \phi^{2}}\right] \\
\frac{f_{0}^{2}}{N^{2}}\left(\frac{U}{a \cos \phi}\left[\frac{\partial\{\psi\}}{\partial \lambda} \frac{\partial\{\psi\}}{\partial z}-\{\psi\} \frac{\partial^{2}\{\psi\}}{\partial \lambda \partial z}\right]+\frac{V}{a}\left[\frac{\partial\{\psi\}}{\partial \phi} \frac{\partial\{\psi\}}{\partial z}-\{\psi\} \frac{\partial^{2}\{\psi\}}{\partial \phi \partial z}\right]\right)
\end{array}\right)+\mathbf{C}_{U} M,
$$


from the negative to positive lag is then traced to estimate the actual phase propagation (Blackmon et al. 1984). Finally, the local value of $c_{p}$ at that grid point is determined as the projection of this phase propagation onto the direction of the local basic flow $\mathbf{U}$. The phase propagation vector $\mathbf{C}_{U}$ is determined by both $c_{p}$ and the basic flow. More details for calculating $\mathbf{W}$ are referred to Takaya and Nakamura (2001).

The MJO phases are determined by the revised real-time multivariate MJO index (RMM-r; Liu et al. 2016). The RMM-r represents notably more variance in convection at zonal wavenumbers 2-5 compared to the original RMM index (Wheeler and Hendon 2004), in which zonal winds play a dominant role (Straub 2013; Wolding and Maloney 2015). The RMM-r index better balances the roles of OLR and winds and substantially enhances the OLR magnitude over the Eastern Indian-Western Pacific Oceans. Although a strict balance is reached by the newer RMM-b index (Liu 2018), the RMM-r identifies the MJO phases similar to the RMM-b (not shown). In this study, strong MJO events are those with RMM-r amplitudes greater than 1 and persistent for longer than 20 days. Totally 112 strong MJO cases occurred in the wintertime from 1979/1980 to 2013/2014. The phases $1-8$ of each MJO event are determined by the RMM1 and RMM2 signs on the RMM-r phase diagram. For example, phases 1 and 8 correspond to enhanced MJO convection in Africa and the Western Hemisphere, 2 and 3 in the Indian Ocean, 4 and 5 in the Maritime Continent, and 6 and 7 over the Western Pacific, respectively. It is noteworthy that the first four phases span longer in time than the last four when the MJO propagates faster.

The reconstructed OLR used for composite analysis are derived in the following steps. We first remove the climatology as the first four harmonics of the annual cycle and then subtract the 120-day retrospective average from the daily OLR, U850 and U200. Next, we scale the OLR, U850 and $\mathrm{U} 200$ with $\left(2 \mathrm{~W} \mathrm{~m}^{-2}, 1 \mathrm{~m} \mathrm{~s}^{-1}\right.$ and $\left.1 \mathrm{~m} \mathrm{~s}^{-1}\right)$ to better balance the roles of the OLR and zonal winds. A combined EOF (CEOF) analysis is applied to the resultant anomalies in $30^{\circ} \mathrm{S}-30^{\circ} \mathrm{N}$, and then the reconstructed OLR is obtained by projecting the anomalies onto the first two CEOF modes. These steps yield similar results to a band-filter at 20-100 days (not shown), while they would potentially be more useful for forecast indications.

\subsection{Model}

In this study, a linear baroclinic model (LBM) is used to verify the responses in the mid latitudes to the tropical heating at different locations corresponding to specific MJO phases. The LBM model was developed from primitive equations (Watanabe and Kimoto 2000; Watanabe and Jin 2003) and has been used for analyzing Rossby wave propagation under different forcing (Annamalai and Sperber 2005; Ham et al.
2007; Cui et al. 2015; Zhang et al. 2016). The model has a horizontal resolution of spectral triangular truncation at wavenumber 42 (T42), and a vertical resolution of 20 vertical levels in the sigma coordinate system. Vertical diffusion and bi-harmonic horizontal diffusion with a time scale of $6 \mathrm{~h}$ are employed for smoothing. Rayleigh friction and Newtonian damping are applied using time scales of $(0.5 \text { day })^{-1}$ for $\sigma \geq 0.9,(1 \text { day })^{-1}$ for $\sigma \leq 0.3$, and $(20 \text { day })^{-1}$ for other sigma levels. The 1958-1997 DJF (December-February) climatology readily from NCEP-NCAR Reanalysis (Kalnay et al. 1996) is employed as the basic state.

\section{Dominant patterns of winter-time intraseasonal SAT over the CONUS}

The variances of raw, subseasonal (5-120 days), and intraseasonal (20-100 days) SAT anomalies, the percentage of subseasonal to raw variance, and the percentage of intraseasonal to subseasonal variance are shown in Fig. 1 to examine the spatial distributions of the SAT variability during the DJFM seasons from 1979/1980 to 2013/2014. The variances in raw, subseasonal, and intraseasonal daily SAT anomalies have very similar patterns in that maximum centers are located over the central-northern CONUS, but with different magnitudes (Fig. 1a-c). Percentages greater than $72 \%$ of the subseasonal to the total variance cover the western CONUS (Fig. 1d) with the minimum at the southern part also exceeding $60 \%$. The percentage of intraseasonal to subseasonal variance is similarly distributed (Fig. 1e): it is greater than $36 \%$ over the entire CONUS with two maxima exceeding $48 \%$ over the northwestern corner and along the southwestern coast. The patterns in Fig. 1 indicate that the subseasonal component (5-120 days) dominates the SAT variability over the CONUS during boreal winter and it has a notable component at intraseasonal (20-100 days) time scales.

The dominant patterns of the winter-time intraseasonal SAT over the CONUS are derived by EOF analysis on the 20-100-day filtered SAT anomalies for the DJFM seasons between 1979/1980 and 2013/2014 (Fig. 2). The first two leading EOFs explain $53.8 \%$ and $20.5 \%$ of the total intraseasonal variance, respectively; both are well separated from each other and from the rest of the EOF modes according to the criteria of North et al. (1982). The first EOF is characterized by a monopole pattern (Fig. 2a) with large positive loadings covering the entire CONUS and a maximum centering the central-northern US. The second mode (EOF2) has a dipole pattern with opposite loading signs over the northwestern and southeastern CONUS (Fig. 2b). A positive (or negative) phase of the EOF1 corresponds to above (or below) normal SATs over most parts of the CONUS, while a positive phase of the EOF2 represents warm SATs in the 

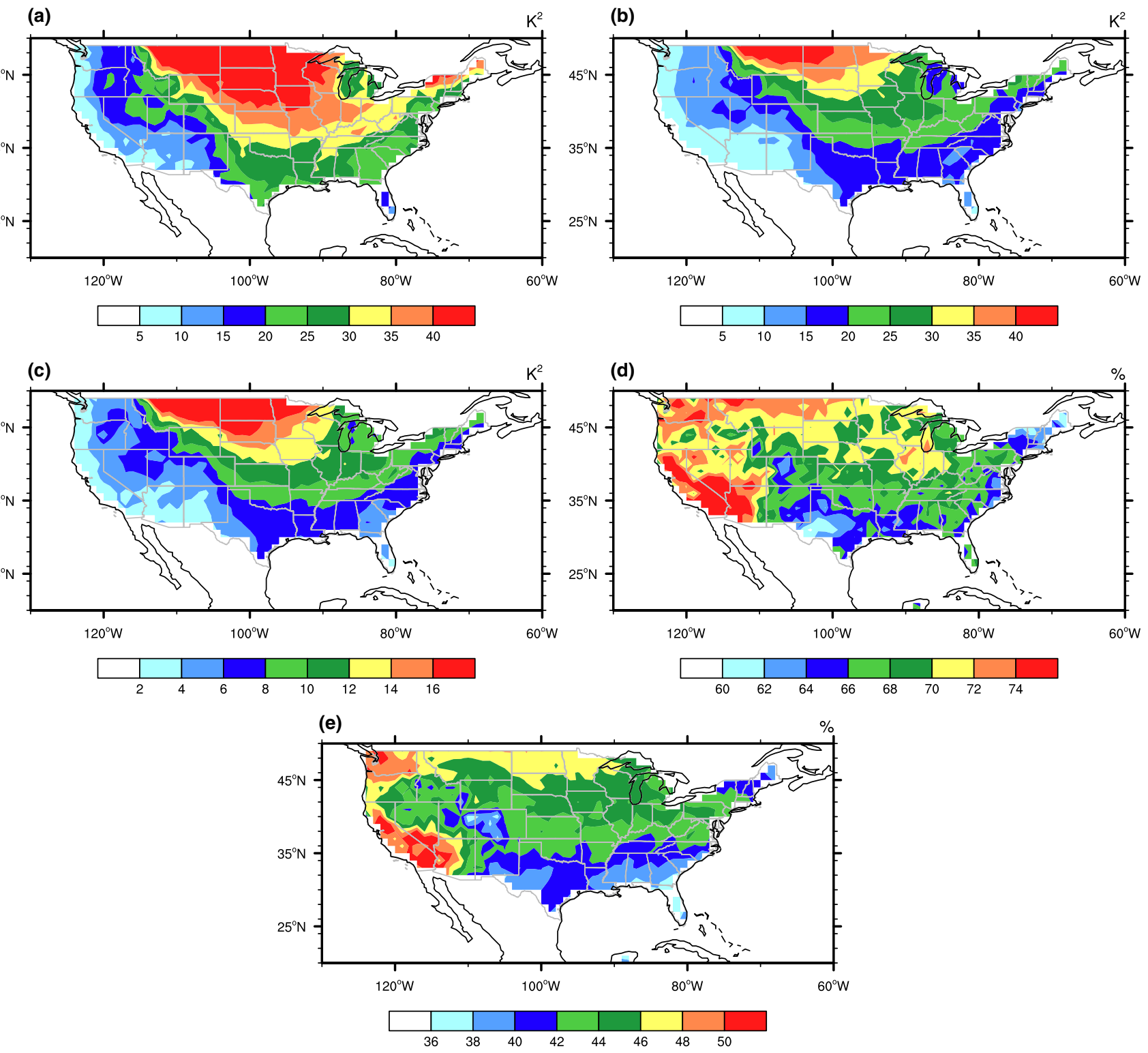

Fig. 1 Variances $\left(\mathrm{K}^{2}\right)$ of a total daily anomalies for the surface air temperature (SAT), b subseasonal SAT, c 20-100-day filtered SAT and percentage variances (\%) of $\mathbf{d}$ subseasonal over total daily SAT anomalies and e 20-100-day filtered over the subseasonal SAT across the Contiguous United States (CONUS) during the winter seasons (DJFM) between 1979/1980 and 2013/2014 northwestern CONUS and cold SATs in the southeastern CONUS, and a negative phase reverses the signs. The second leading mode is similar to the winter temperature dipole over North America disclosed by Singh et al. (2016). This dipole pattern occurred during the winters of 2013/2014 and 2014/2015 when much of the western CONUS suffered exceptionally warm and dry conditions and the central and eastern CONUS experienced frequently cold air outbreaks with severe winter storms from the Arctic. This concurrent "warm-West/cool-East" SAT pattern over the CONUS has become substantially more frequent in recent years (Singh et al. 2016). Since the pattern is clearly represented by the
EOF2 mode, investigating this mode and its relevant mechanisms are meaningful even though it explains a smaller variance than the first EOF mode.

The first two EOF modes have a lead-lag correlation (Fig. 3). The positive PC2 leads the positive PC1 by approximately 5-7 days with a correlation coefficient of 0.3 passing the 95\% significance level. This correlation indicates that the monopole pattern of the EOF1 has a significantly lagged relationship with the dipole pattern of the EOF2: the positive loading of the EOF2 over the western CONUS moves eastward until it covers most parts of the CONUS to become a monopole pattern of the EOF1 approximately 

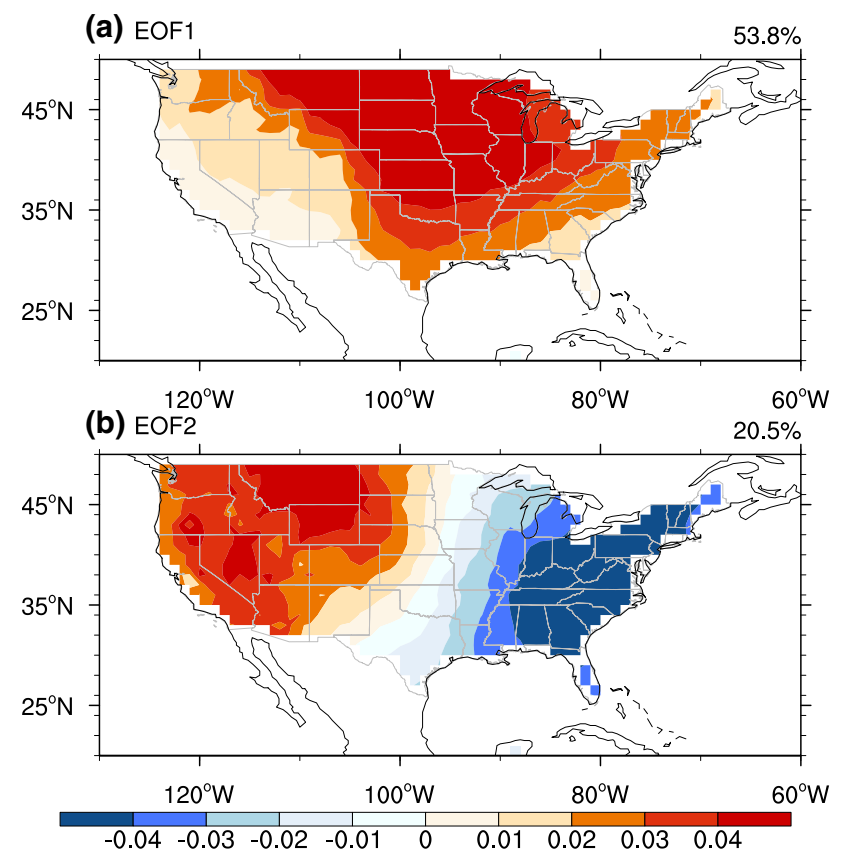

Fig. 2 First two EOF modes for the 20-100-day filtered SAT anomaly across the CONUS during the winter seasons (DJFM) between $1979 / 1980$ and 2013/2014

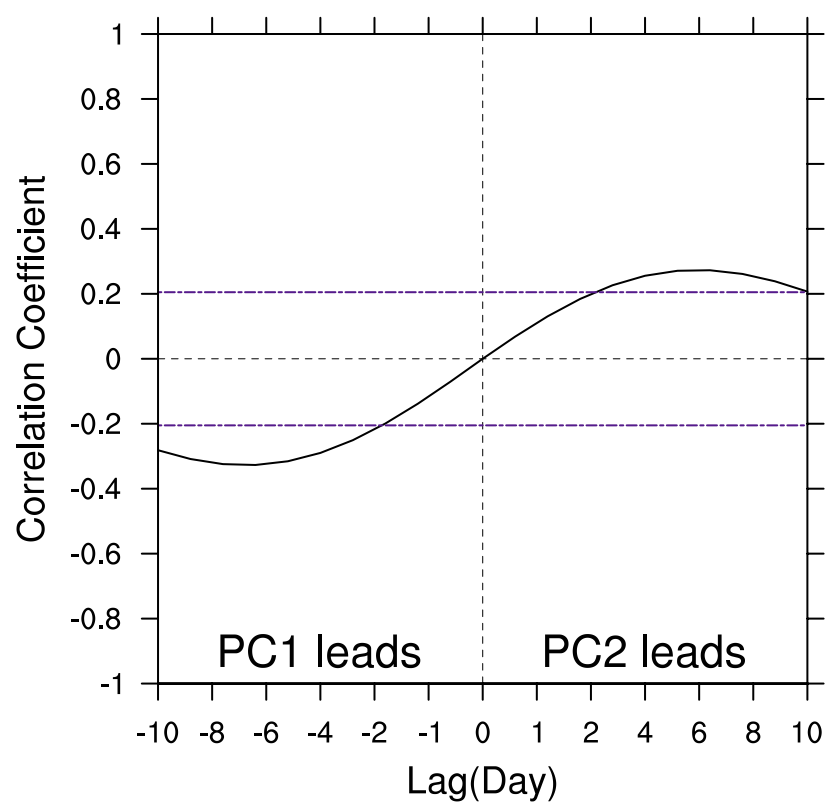

Fig. 3 Lead-lag correlation coefficients between the PC1 and PC2 for the winter seasons (DJFM) between 1979/1980 and 2013/2014. Purple dashed lines represent the $95 \%$ confidence level

7 days later. The correlation also suggests that the PC1 and PC2 are dependent on each other and may share similar physical origins and predictability sources.
The two SAT EOF patterns over the CONUS are connected with the tropical MJO forcing through the intraseasonal anomalies of the 500-hPa geopotential height (Z500). The connections are established with composite maps lagging $-15 \sim 0$ days. The composites on Lag 0 day for a High (or Low) correspond to the average of Z500 and SAT anomalies when the normalized PC1 is greater than 1 (or smaller than -1$)$. The composites on Lag $-n$ days represent the average of the Z500 and SAT preceding the PCs above or below normal by $n$ days. Consequently, lagged difference composites are derived by the difference between High and Low composites on specific lag days to enhance the signal. There are 552, 579, 639, and 617 cases for the conditions of PC1 > 1STD, PC1 <-1STD, PC2 > 1STD, and $\mathrm{PC} 2<-1 \mathrm{STD}$, respectively.

Figure 4 shows the lagged difference composite maps of the intraseasonal SAT and the 500-hPa geopotential height anomalies with respect to the normalized PC1 in the winter seasons (DJFM) from 1979/1980 to 2013/2014. On Lag day -15 (Fig. 4a), negative SAT anomalies cover the entire CONUS with a center over the central-northern CONUS and a corresponding minimum of Z500. Cold SAT anomalies start to decrease with the center moving to the eastern CONUS, while positive Z500 anomalies intensify and cover the western CONUS where warm SAT anomalies begin to develop (Fig. 4b, c). Afterwards, on Lag day -6 , the positive SAT and Z500 anomalies further intensify and occupy the CONUS with a center over the central-northern CONUS (Fig. 4d). Finally, the positive SAT anomalies reach their maxima with values greater than $2.5 \mathrm{~K}$ on Lag day 0 (Fig. 4f). Notably, the composite anomalies mostly have a monopole pattern of the EOF1 since they are based on the normalized PC1. The anomalies become a dipole pattern with a weak magnitude when transitioning from negative to positive values around Lag day -9 , indicating that this evolution from Lag day -9 to 0 is different from the lead-lag relationship between the two PCs with a maximum correlation at Lag day -6 (cf. Fig. 3).

Figure 5 similarly shows the lagged difference composite maps for the evolution of the intraseasonal SAT and Z500 anomalies with respect to the normalized PC2 in high and low values. On Lag day -15 (Fig. 5a), both the SAT and Z500 have a dipole pattern with a cold SAT and negative Z500 in the western CONUS and a warm SAT and positive Z500 in the eastern CONUS. Subsequently, the cold SAT gradually moves eastward then covers the entire CONUS (Fig. 5b, c). Afterwards (Fig. 5d), the cold SAT intensifies and covers the eastern CONUS with a center in the middle Mississippi Valley, Ohio and Tennessee Valleys, and the negative Z500 also strengthens but with a center in the northeastern corner of the CONUS. The positive Z500 anomaly in the western CONUS further intensifies; as a result, a warm SAT develops (Fig. 5e). The dipole patterns 
(a) Lag -15

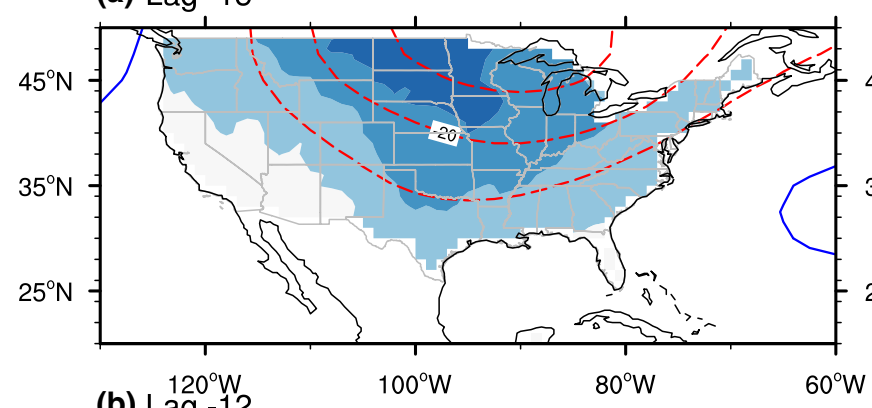

(b) $\operatorname{Lag}-12$

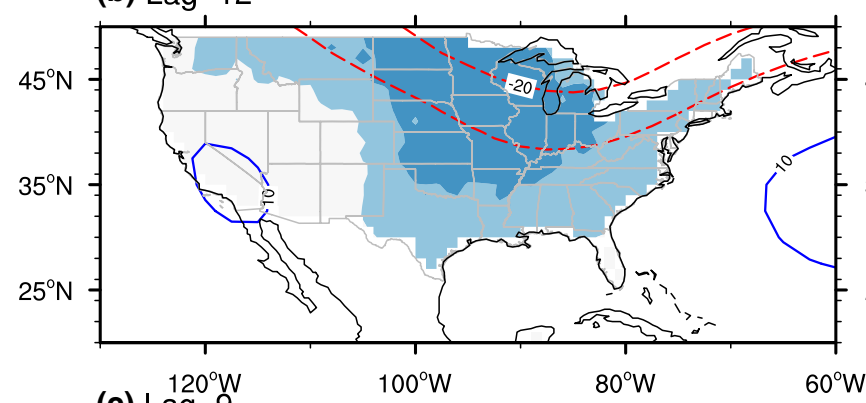

(c) $\mathrm{Lag}-9$

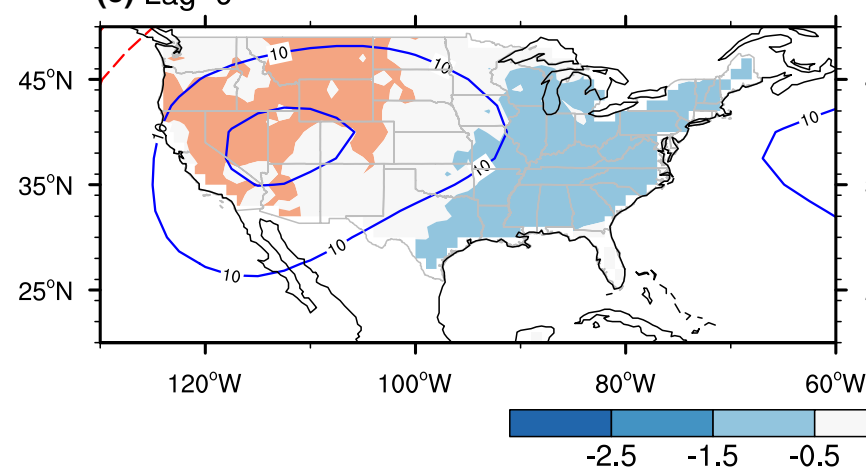

(d) Lag -6

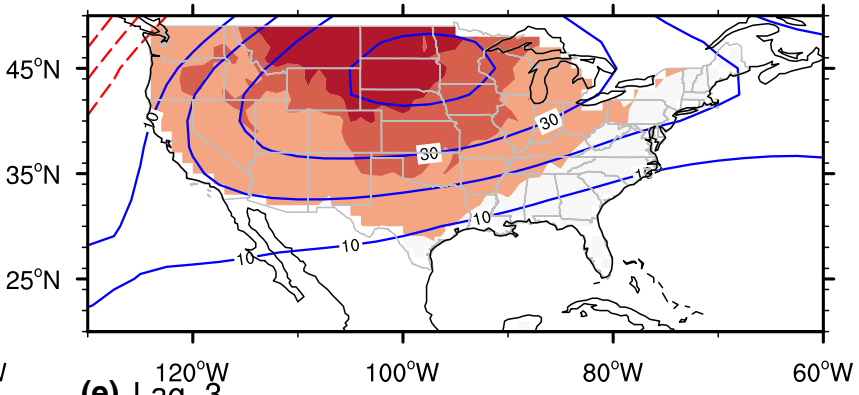

(e) $\operatorname{Lag}^{120^{\circ} \mathrm{W}}$

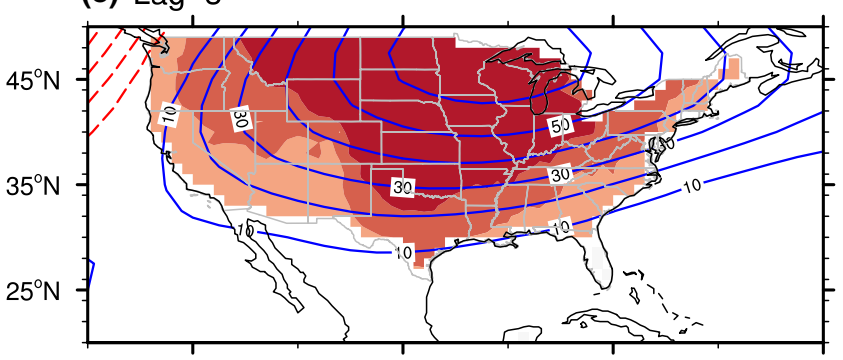

(f) $\operatorname{Lag} 0^{120^{\circ} \mathrm{W}}$

$60^{\circ} \mathrm{W}$

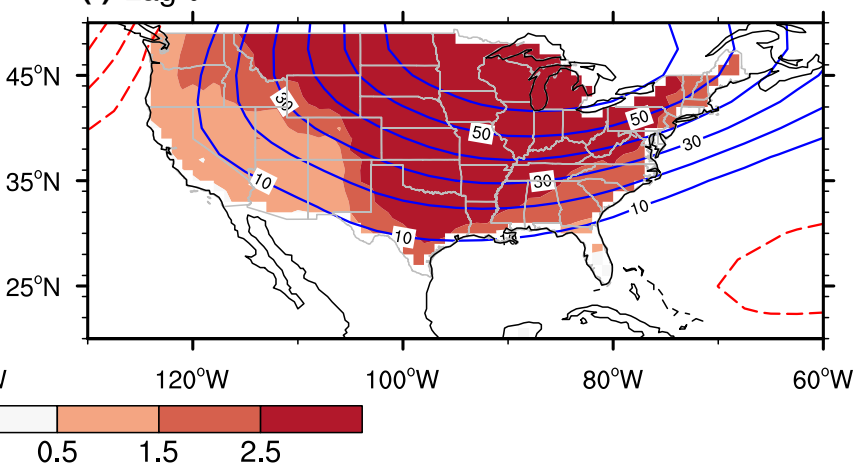

Fig. 4 Lagged difference (diff = high - low) composite maps of the 20-100-day filtered SAT (shading; K) and 500-hPa geopotential height (contours; gpm) anomalies associated with the normalized PC1

of the SAT and Z500 further develop and reach the maxima on Lag day 0 (Fig. 5f).

The above lagged composite maps demonstrate that (1) the negative EOF1 monopole pattern evolves into a dipole pattern and develops back into an EOF1 monopole pattern after 15 days and (2) the negative EOF2 dipole pattern first turns into a monopole pattern and then develops back into an EOF2 dipole pattern 15 days later. Correspondingly, positive and negative Z500 anomalies precede warm and cold SAT anomalies in situ, which indicates that the intraseasonal SAT over the CONUS is closely modulated by eastward propagating Z500 anomalies.

Next, the terms in Eq. (1) at $1000 \mathrm{hPa}$ are compared in time evolutions for their contributions to the generation of the monopole SAT warming in association with the PC1 (cf. Fig. 4). Figure 6 shows the evolution of the lagged composites averaged between $35^{\circ}-45^{\circ} \mathrm{N}$ in a time-longitude section. Warm anomalies start on Lag day -13 , causing the surface temperature tendency to maximize at $95^{\circ} \mathrm{W}$ by Lag day -6 (Fig. 6a). The dynamic terms, including the horizontal advection (Fig. 6c) and adiabatic vertical advection (Fig. 6d), first collectively contribute cold anomalies from Lag days -15 to -12 , and then change to strong warm anomalies in the eastern CONUS (Fig. 6b). A close inspection indicates that the horizontal advection (Fig. 6c) evolves more consistently with the dynamic term than the diabatic process. Specifically, the horizontal advection of the basic-state temperature by intraseasonal winds agrees with the total horizontal advection term in the eastern CONUS (Fig. 6c, g), while the advection of the intraseasonal temperature by the time mean flow (Fig. 6f) contributes to the warming from Lag days -15 to -9 and the cooling from Lag day -8 and onward in the western CONUS. Different from the horizontal advection terms, the adiabatic heating has a weak warming center near $105^{\circ} \mathrm{W}$ and a weak cooling center at $92^{\circ} \mathrm{W}$ from Lag days -8 to 0 (Fig. 6d). 
(a) Lag -15

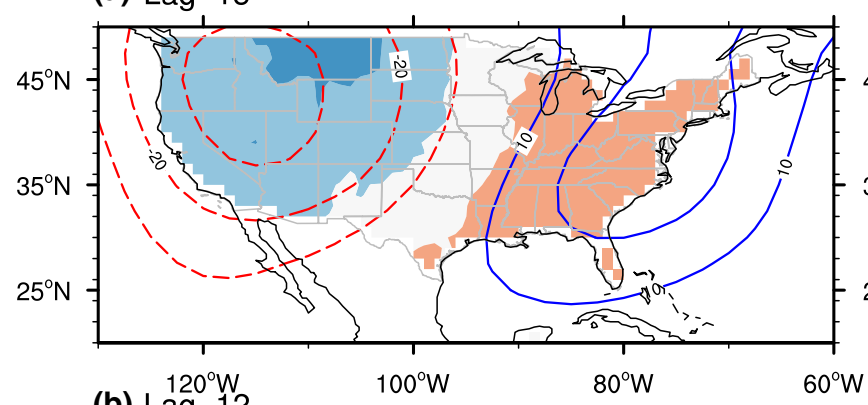

(b) $\operatorname{Lag}-12$

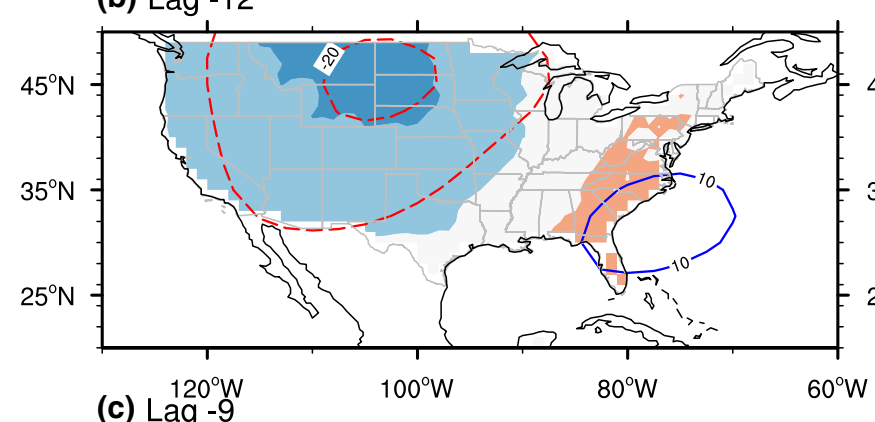

(c) $\begin{gathered}120^{\circ} \mathrm{W} \\ \operatorname{Lag}-9\end{gathered}$

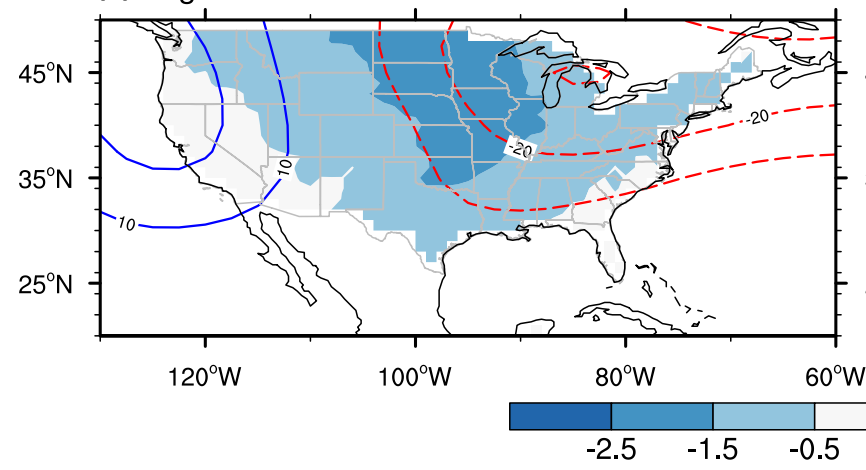

(d) Lag -6

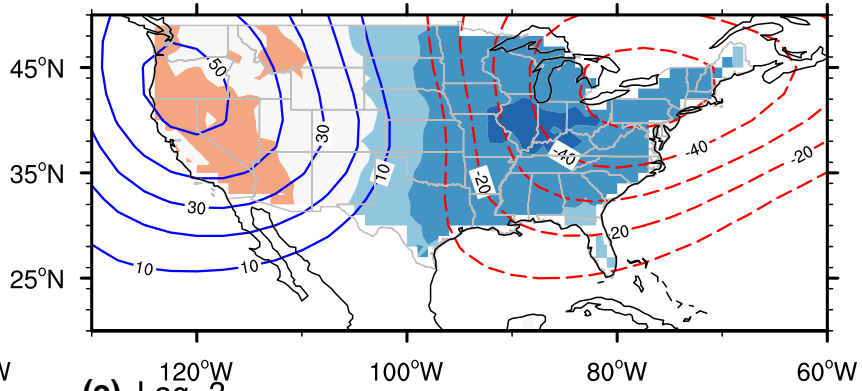

$60^{\circ} \mathrm{W}$
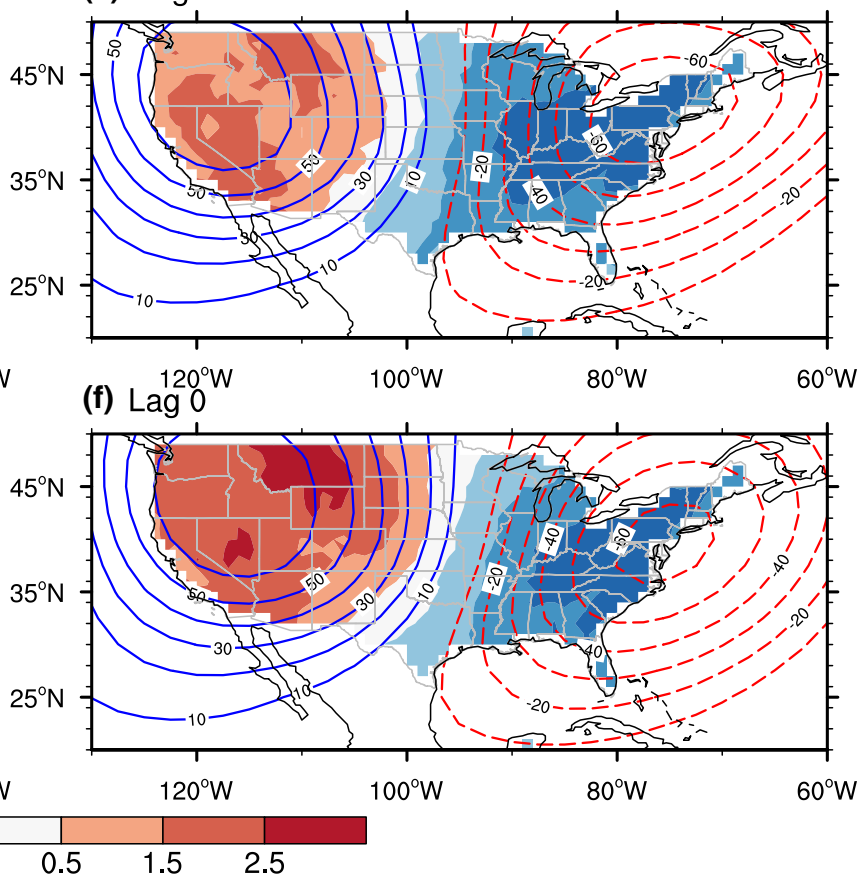

Fig. 5 Same as Fig. 4 but for the normalized PC2

The diabatic processes (Q1, Fig. 6e) contribute oppositesign temperature tendencies and counteract the effects of the dynamic processes in the eastern CONUS. Among the adiabatic terms, the vertical advection of the time mean temperature by the intraseasonal vertical velocity is dominant (Fig. 6h). These results indicate that the monopole warming over the CONUS is mainly determined by the horizontal warm advection.

Figure 7 is similar to Fig. 6 but in association with the normalized PC2 for the dipole pattern of the SAT. It is characterized by a warm center in the northwestern CONUS and a cold center in the southeastern (cf. Fig. 5f). The surface temperature increases in the west of $105^{\circ} \mathrm{W}$ from Lag days -11 to -1 , and decreases in the east of $105^{\circ} \mathrm{W}$ from Lag days -15 to -3 (Fig. 7 a). The warming in the western CONUS is evidently induced by the dynamic term since Lag day -9 , while the cooling in the eastern CONUS starts at Lag day -6 (Fig. 7b). Overall, the horizontal advection and the dynamic term contribute similarly to the cooling in the east of $110^{\circ} \mathrm{W}$ (Fig. 7c), while the adiabatic vertical motion contributes majorly to the warming in the west of $110^{\circ} \mathrm{W}$ (Fig. 7d). The diabatic term presents an effect opposite to the dynamic term from Lag days -9 to 0 (Fig. 7e). In the thermodynamic budget, the horizontal advection of intraseasonal temperature by the time mean flow induces warming within the longitude band of $100^{\circ}-110^{\circ} \mathrm{W}$ from Lag days -12 to 0 (Fig. $7 \mathrm{f}$ ). The horizontal advection of time mean temperature by the intraseasonal horizontal flow plays a dominant role in cooling the eastern CONUS (Fig. 7g). In summary, the adiabatic vertical motion contributes to the warming in the west of $110^{\circ} \mathrm{W}$ and the horizontal advection is responsible for the warming between $100^{\circ} \mathrm{W}$ and $110^{\circ} \mathrm{W}$ and the cooling in the eastern CONUS. The radiation effect associated with the PC1 and PC2 counteracts the positive effects of the dynamic processes on SAT anomalies. The net radiation flux (not shown) has evolution patterns similar to those of the Q1 (Figs. 6e, 7e). 
Fig. 6 Time-longitude diagram of lagged composites for the thermodynamic equation terms (shaded; $\mathrm{K} \mathrm{day}^{-1}$ ) at $1000 \mathrm{hPa}$ : a tendency term, $\mathbf{b}$ dynamic (advective + adiabatic) term, c horizontal advection term, d adiabatic vertical motion term, e Q1 term, $\mathbf{f}$ horizontal advection of intraseasonal temperature by the time mean flow, $\mathbf{g}$ horizontal advection of time mean temperature by the intraseasonal horizontal flow, and $\mathbf{h}$ vertical advection of time mean temperature by the intraseasonal vertical flow associated with the normalized PC1. All variables are averaged along latitudes $35^{\circ}-45^{\circ} \mathrm{N}$. Only the terms statistically significant at the $95 \%$ level of the Student's- $t$ test are plotted (a) $T$ tendency

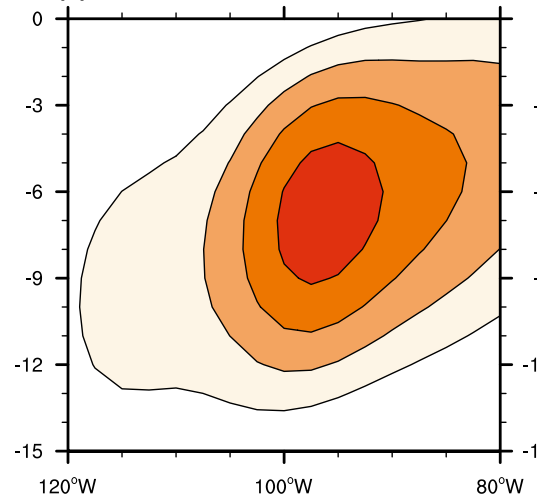

(c) Horz. adv. (b) Dyn.

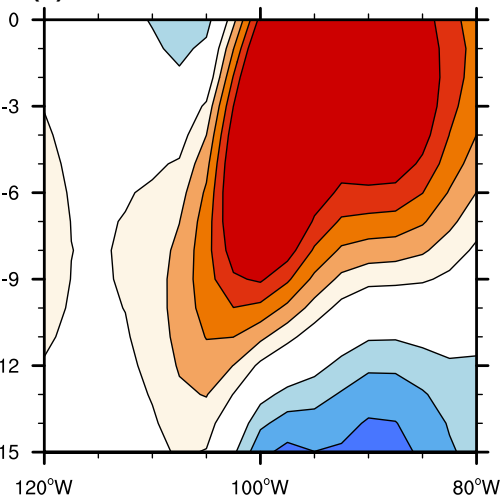

(d) Adia.
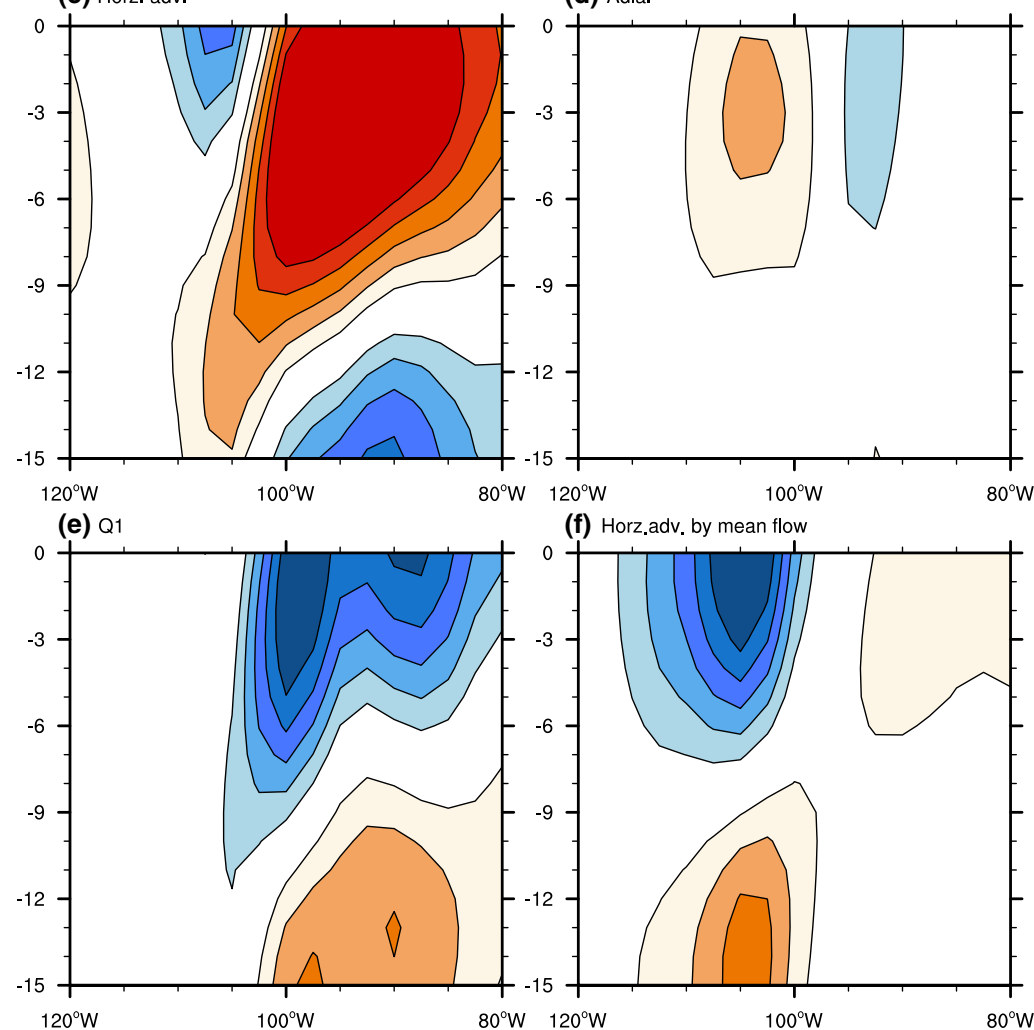

(f) Horz.adv. by mean flow

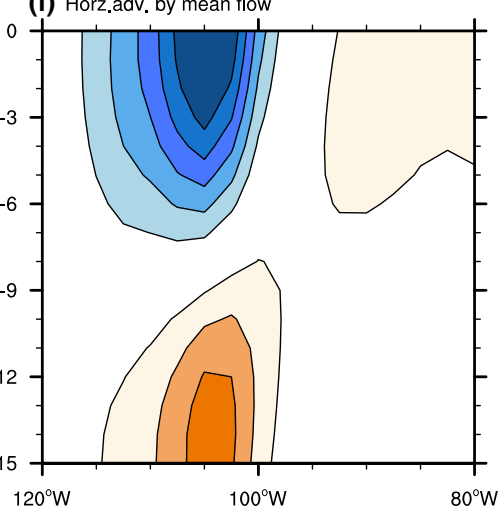

(g) Horz.adv. by MJO flow

(h) Vert.adv. by MJO flow

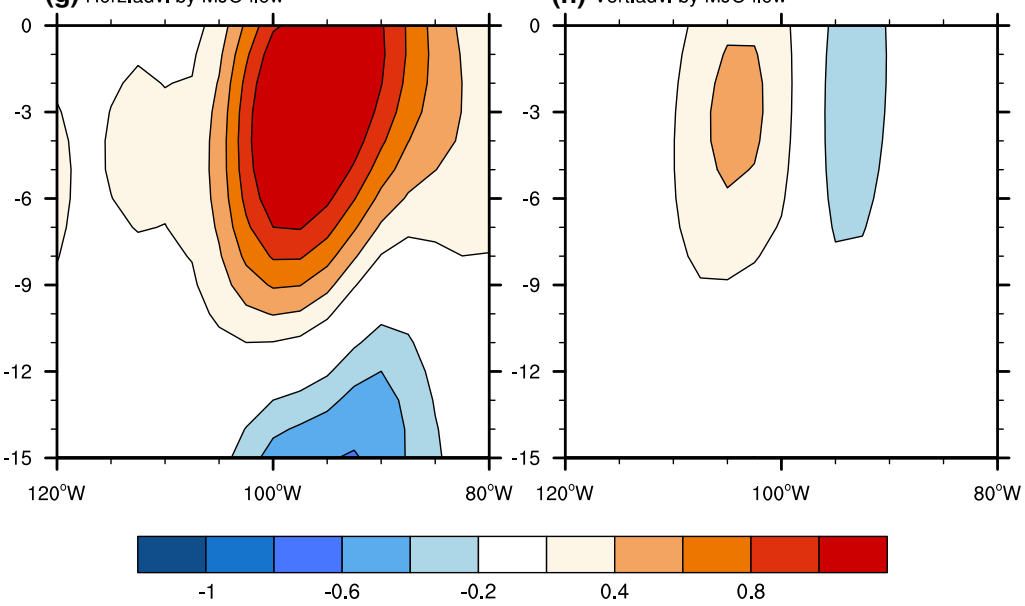


Fig. 7 Same as Fig. 6 but for the normalized PC2 (a) $\mathrm{T}$ tendency

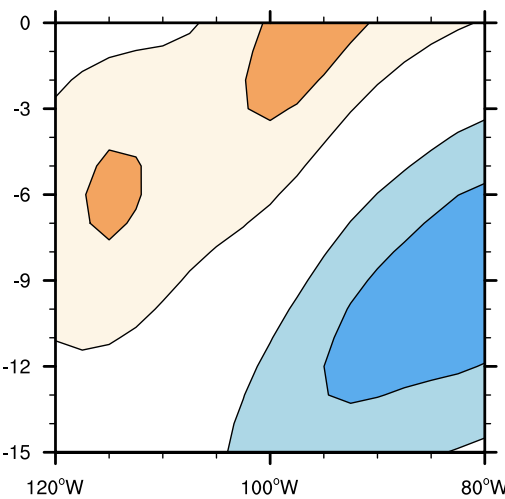

(c) Horz. adv.

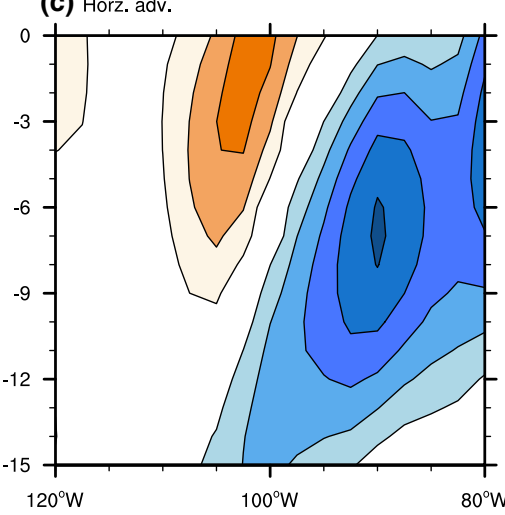

$120^{\circ} \mathrm{W}$ (b) Dyn.

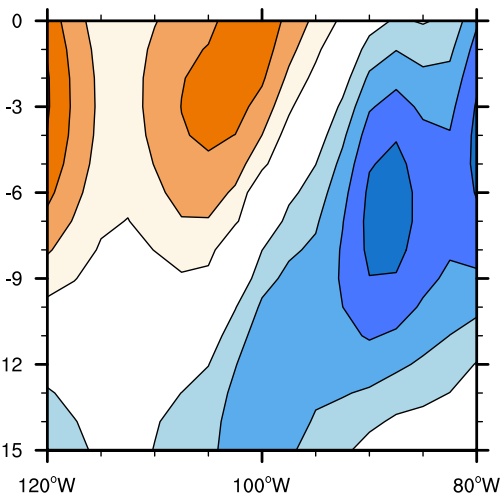

(d) Adia.
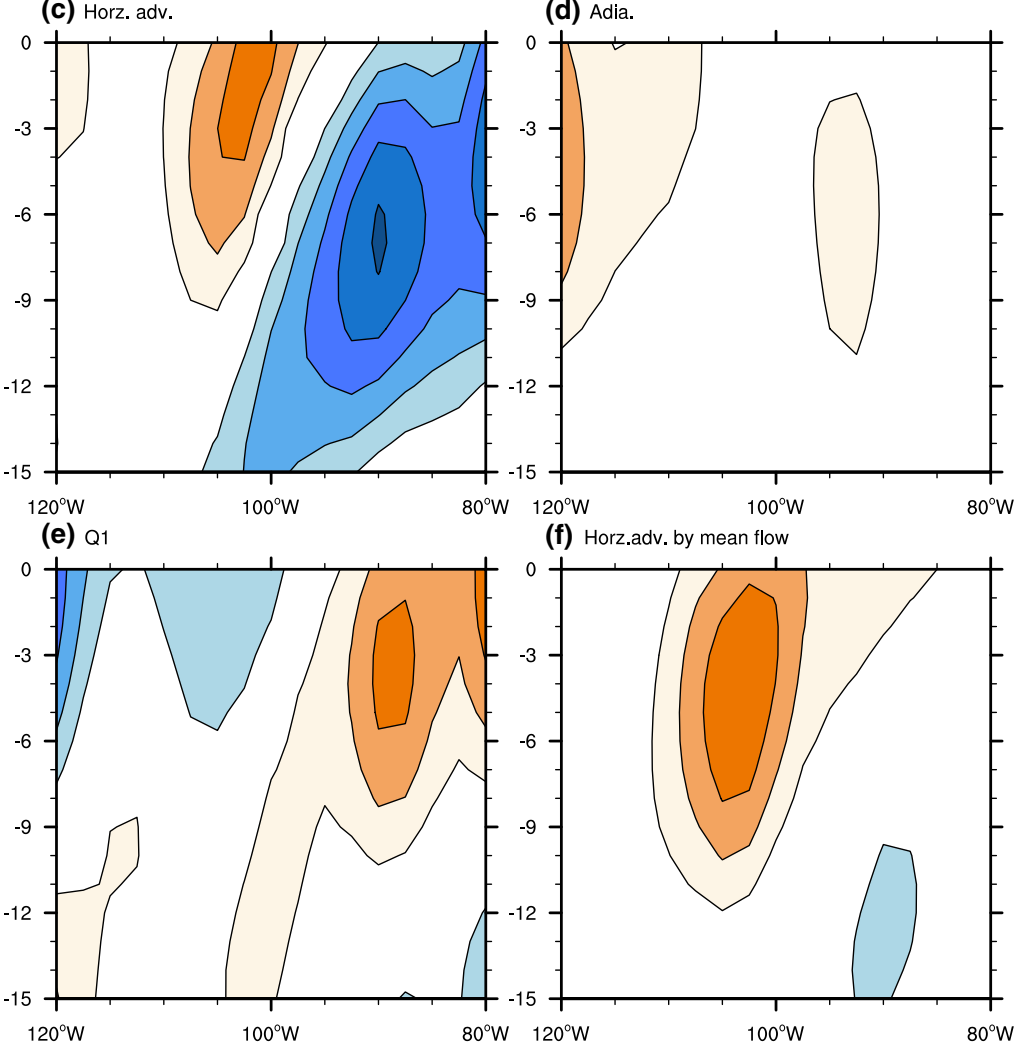

(f) Horz.adv. by mean flow

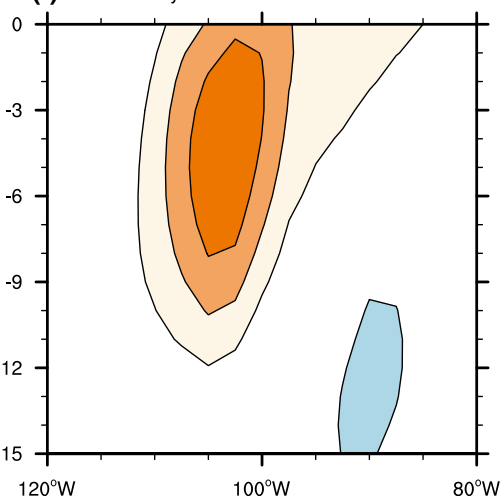

(g) Horz.adv. by MJO flow

(h) Vert.adv. by MJO flow

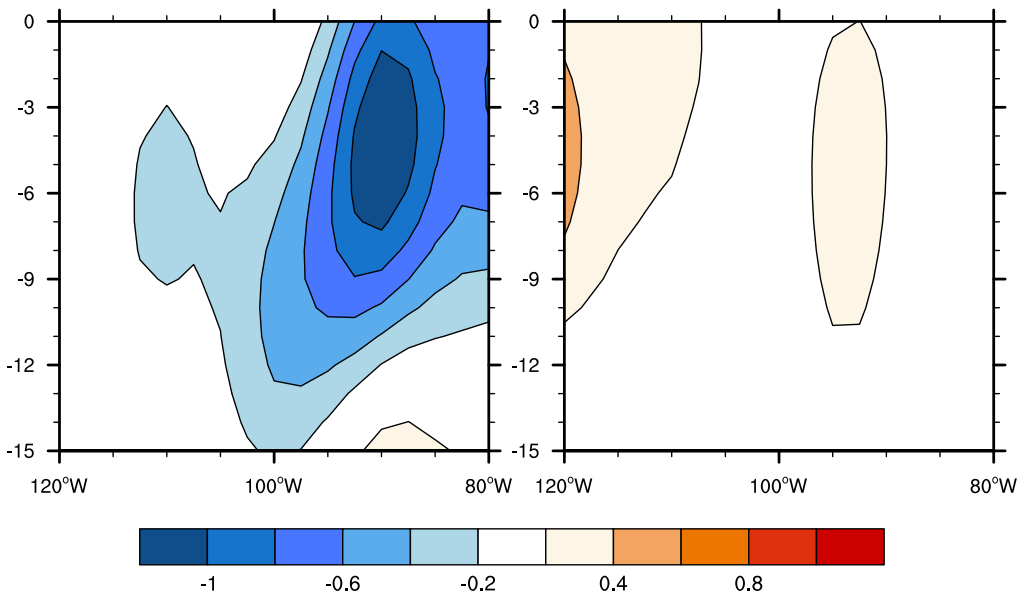




\section{Influence of MJO convection on the EOF1 and EOF2 SAT patterns}

The intraseasonal variations in the SAT over the CONUS are related to mid-latitude Rossby waves in response to tropical MJO forcing (e.g., Matsueda and Takaya 2015). These connections are next established using composite maps with respect to the first two EOF modes of the SAT. The connections are present in the atmospheric circulations at $200 \mathrm{hPa}$, isobaric vertical motion at $500 \mathrm{hPa}$, OLR anomalies reconstructed from the RMM-r modes, and wave activity flux $\mathbf{W}$. The difference (between High and Low) composites of filtered variables and the reconstructed OLR are derived in association with the PC time series leading from 15 to 0 days, as MJO convection tends to lead the SAT anomalies over the CONUS by $2-3$ weeks through the propagation of Rossby waves (Jin and Hoskins 1995; Seo and Son 2012). The atmospheric circulations at $850 \mathrm{hPa}$ (not shown) are also associated with the monopole and dipole modes of the SAT over the CONUS; the patterns are similar to those at $500 \mathrm{hPa}$ and evolve consistently with alternating EOF1 and EOF2 modes.

The OLR patterns reconstructed from the RMM-r modes represent tropical MJO convections in real-time applications (Liu et al. 2016), although the OLR filtered at 20-100 days generates similar composites. Figure 8 shows the lagged composites of the 20-100-day filtered streamlines (gray vectors) and stream functions at $200 \mathrm{hPa}$ (shading), the reconstructed OLR (red and blue contours) and the horizontal components of the wave activity flux $\mathbf{W}$ (thick black vectors) associated with the normalized PC1. The plotted streamlines are statistically significant at the $95 \%$ confidence level in either latitudinal or longitudinal winds, and both the stream functions and reconstructed OLR pass the same significance level. On Lag day - 15 (Fig. 8a), a cyclonic anomaly (C2) covers North America; a pair of anticyclonic (A2; positive stream functions) and cyclonic ( $\mathrm{C} 1$; negative stream functions) centers occur over the North Pacific; and a closed anticyclonic anomalous circulation (A1) occurs over the Indian Peninsula and Indo-China Peninsula. Correspondingly, negative OLR anomalies (enhanced convection) extend from the eastern Indian Ocean to the Maritime Continent, while positive OLR anomalies (suppressed convection) are located in the Philippine Sea and equatorial Western Pacific. On Lag day -12 (Fig. 8b), the upper-level circulation and strong MJO convection patterns do not change much. From Lag days -9 to 0 (Fig. $8 \mathrm{c}-\mathrm{f}$ ) the MJO convection weakens with the center moving slightly eastward to the Maritime Continent. Over East Asia, the MJO convection forces an anomalous local Hadley circulation causing adiabatic subsidence to the north (Seo et al. 2016). As a result, the anticyclonic center (A1) moves eastward to South China. On Lag day -9
(Fig. 8c), the eastern Pacific (A3) and western CONUS (A4) are at the center of the southwestern-northeastern tilted positive stream functions, and the $\mathrm{A} 2$ and $\mathrm{C} 1$ diminish westward. Notably, the SAT over the CONUS on this day has a dipole pattern, corresponding to A4 and the weakening negative center in the southeastern US. Three days later (Fig. 8d), C1 disappears, and A3, C2 and A4 intensify. On Lag day - 3 (Fig. 8e), A2 disappears, and A3, C2 and A4 develop further. On Lag day 0 (Fig. 8f), A4 covers the entire CONUS, which causes a uniform warming (cf. Fig. 4f). The evolution of the wave activity flux $\mathbf{W}$ is overlaid on Fig. 8 as thick, black vectors. The waves generally originate from enhanced MJO convections over the equatorial Indian Ocean and then propagate northeastward through the central Pacific (Figs. 8a, b) to North America (Fig. 8c). After Lag day -9, the waves reach east of $180^{\circ}$ and intensify (Fig. $8 \mathrm{c}-\mathrm{f}$ ). The wave energy is continuously transported to the CONUS in developing the anticyclonic center (A4) in the upper troposphere.

Vertical motion is also associated with the MJO convection (represented by the reconstructed OLR) and circulations, which is demonstrated by the lagged difference composites of anomalous vertical velocity and winds at $500 \mathrm{hPa}$ with respect to the normalized PC1 (Fig. 9). On Lag day -15 , negative vertical velocity (ascending) is centered on the tropical Indian Ocean, which corresponds to enhanced MJO convection (Fig. 9a). Before Lag day - 9 (Fig. 9a-c), the ascending motion over South China weakens. The motion then descends (Fig. 9d-f) with the convection moving eastward to the Maritime Continent. The MJO forcing induces a quasi-barotropic Rossby wave in the equatorial Indian Ocean propagating northeastward to North America in the upper (cf. Fig. 8) and middle troposphere. This Rossby wave is illustrated by the streamlines for circulation and the vertical motion at $500 \mathrm{hPa}$, which are similar to those at $200 \mathrm{hPa}$. On day Lag -6, middle-level circulations are characterized by an established Rossby wave train, with alternating cyclonic and anticyclonic centers originating from the tropics and propagating to North America, and the circulations are embedded with anomalous ascending or descending motions in between (Fig. 9d). When a large anticyclonic center controls the CONUS, the descending motion develops in situ (Fig. 9c, d) (cf. Fig. 4d). As the positive geopotential height strengthens further, the SAT over the central and eastern CONUS increases rapidly (cf. Fig. 4c) and reaches its peak at Lag day 0 (cf. Fig. 4d). The surface air warming leads to ascending motions over the eastern CONUS (Fig. 9f).

The dipole pattern of the intraseasonal SAT over the CONUS (PC2) is also associated with the MJO forcing through Rossby wave fluxes and lagged circulation patterns. Figure 10 shows the lagged difference composites of the 20-100-day filtered streamlines, stream functions, reconstructed OLR and horizontal components of the wave 
(a) Lag -15

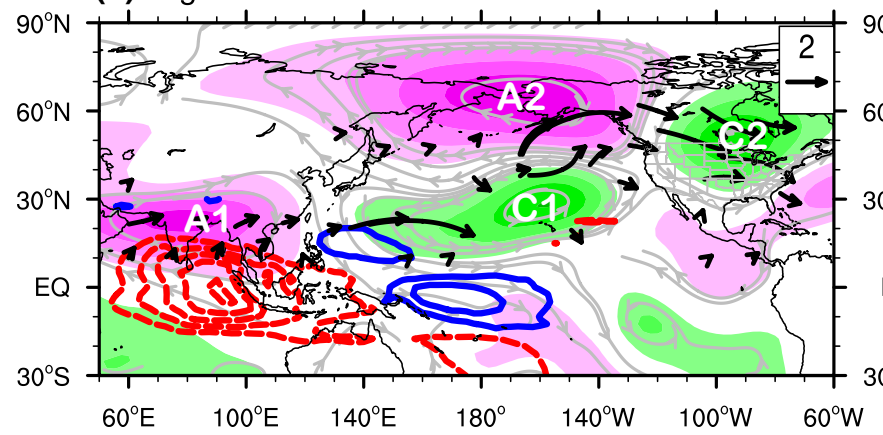

(b) Lag -12

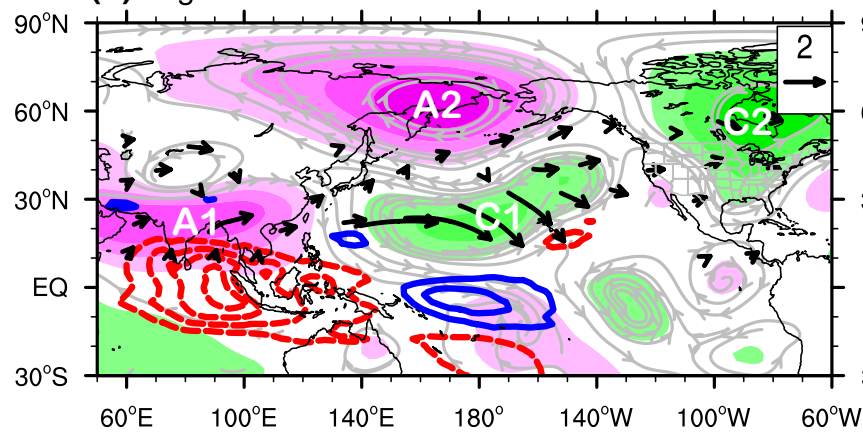

(c) Lag -9

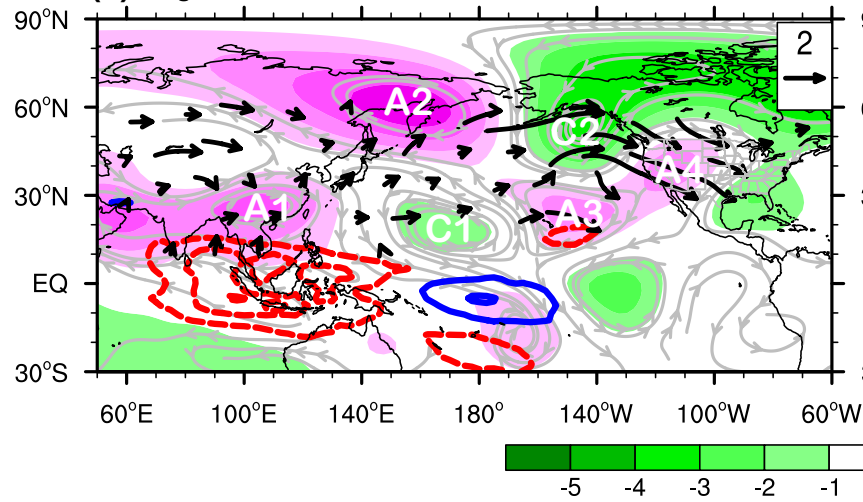

Fig. 8 Lagged difference (diff $=$ high - low) composite anomalies of the 20-100-day filtered 200-hPa streamline, stream function (shading; $10^{6} \mathrm{~m}^{2} \mathrm{~s}^{-1}$ ), reconstructed OLR (contours; $\mathrm{W} \mathrm{m} \mathrm{m}^{-2}$ ) and horizontal components of the wave activity flux $\mathbf{W}$ (vectors; $\mathrm{m}^{2} \mathrm{~s}^{-2}$ ) associated

activity flux $\mathbf{W}$ at $200 \mathrm{hPa}$ associated with the normalized PC2. However, the reconstructed OLR is much smaller than that associated with the PC1. On Lag day -15 , positive OLR anomalies (suppressed convection) are located in the equatorial eastern Indian Ocean, while negative OLR anomalies (enhanced convection) occur over the Philippine Sea. In the meantime, a Rossby wave train is established with a series of cyclonic ( $\mathrm{C} 1$ and $\mathrm{C} 2)$ and anticyclonic (A1 and A2) anomalies from $180^{\circ}$ to North America (Fig. 10a). In the upper troposphere, the cyclonic center (C2) controls the western CONUS and the anticyclonic center (A2) controls the eastern. Three days later (Fig. 10b), the MJO (d) Lag -6

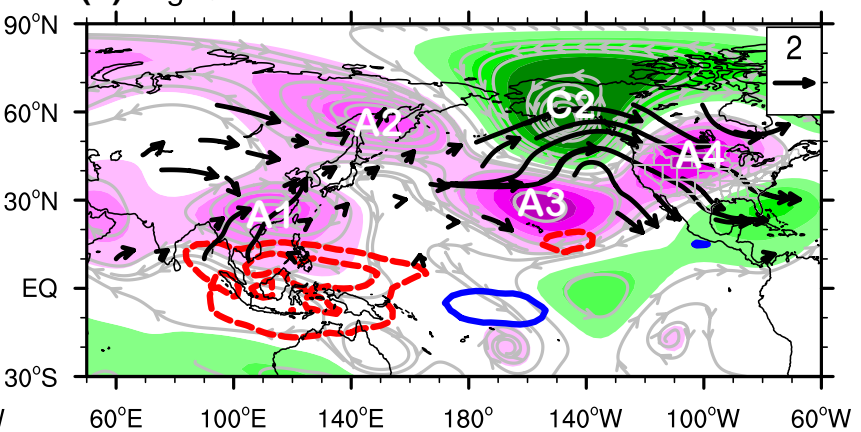

(e) Lag -3

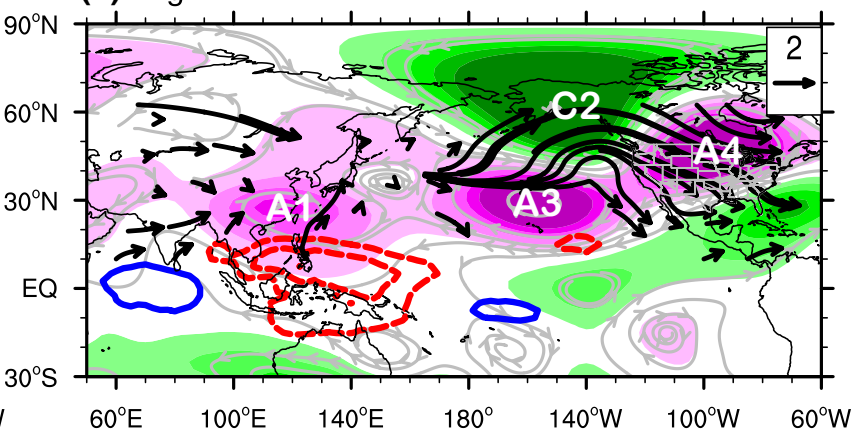

(f) $\operatorname{Lag} 0$

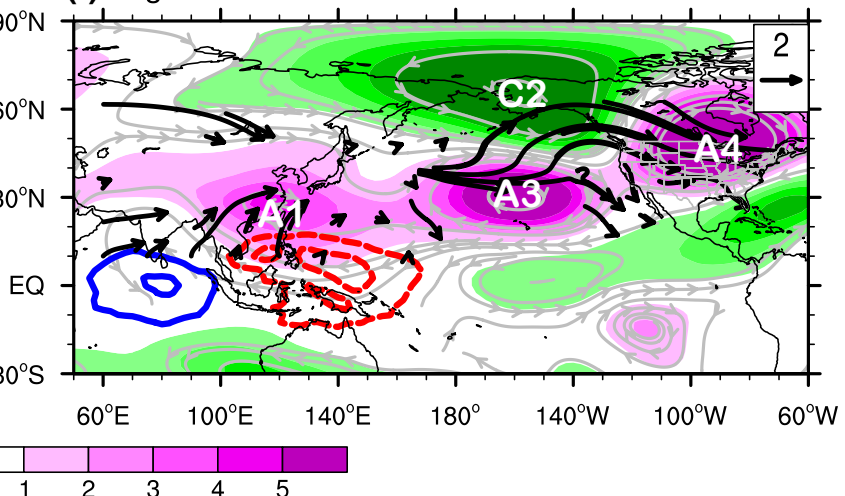

with the normalized PC1. Red dashed contours denote enhanced MJO convection (negative OLR anomaly) and blue solid contours represent suppressed MJO convection (positive OLR anomaly)

convection in the Philippine Sea weakens. To the north, a new anticyclonic circulation (A3) is generated, while the $\mathrm{C} 1$ and A1 move slightly northward. Such an influence of the OLR anomaly in the Philippine Sea on the development and propagation of Rossby wave trains was also disclosed by Seo et al. (2016). On Lag day - 9 (Fig. 10c), a newly formed cyclonic circulation (C3) occurs over South China, north of the positive OLR anomaly (suppressed convection). With the anticyclonic branch (A4) moving from the Polar latitudes, the cyclonic circulation (C2) propagates eastward to the eastern CONUS. From Lag days -6 to 0 (Fig. 10d-f), the cyclonic and anticyclonic 
(a) Lag -15

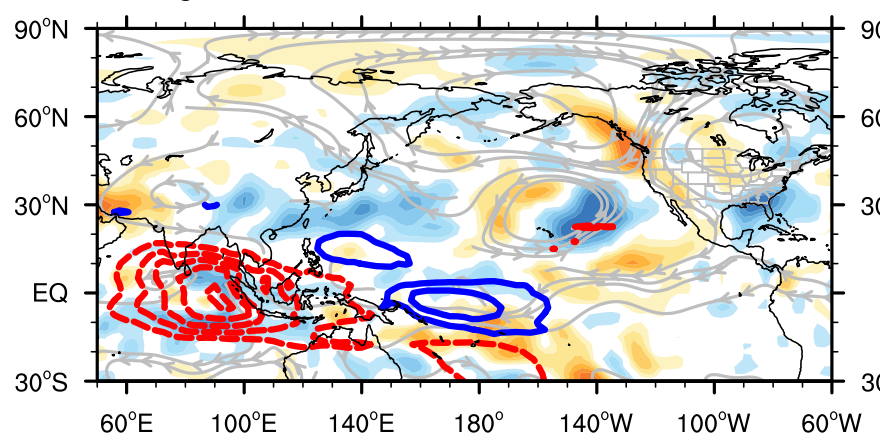

(b) Lag -12

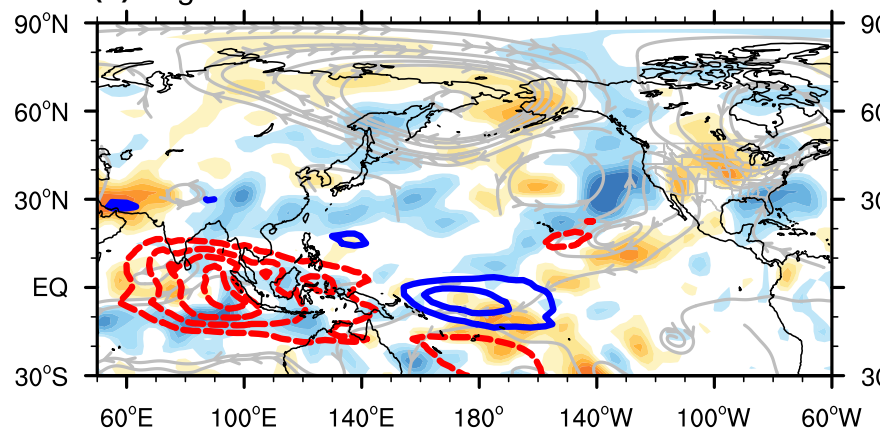

(c) Lag -9

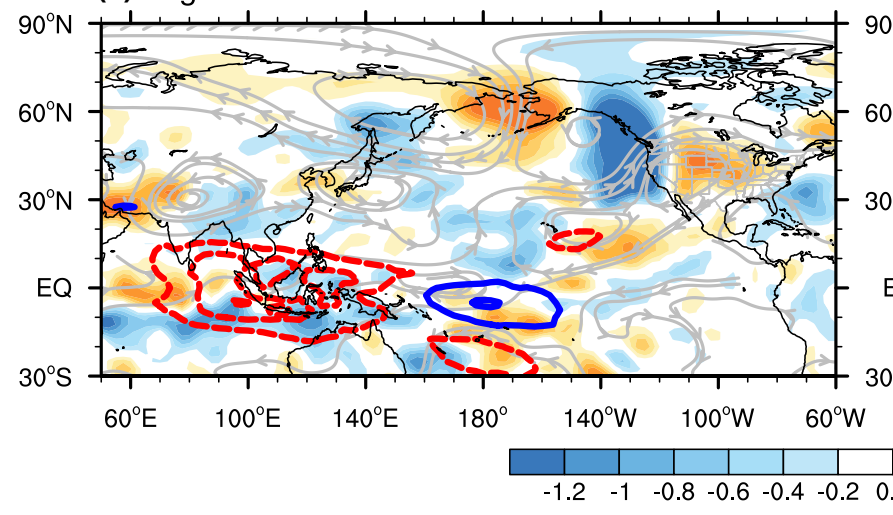

Fig. 9 Lagged difference (diff $=$ high - low) composite anomalies of the 20-100-day filtered $500-\mathrm{hPa}$ streamline, vertical velocity (shading; $\mathrm{hPa} \mathrm{s}^{-1}$ ), and reconstructed OLR (contours; $\mathrm{W} \mathrm{m}{ }^{-2}$ ) associated

centers (A3, C1, A4, and C2) are strengthened further. The western and eastern CONUS are controlled by the anticyclone $\mathrm{A} 4$ and cyclone $\mathrm{C} 2$, respectively, in the upper troposphere, which corresponds to the warm-West/coolEast dipole pattern of the SAT (cf. Fig. 5f). The wave activity flux shows that the wave energy originates from the anticyclonic center (A3) in the central Pacific and is induced by the convection in the equatorial Pacific on Lag day -12 (Fig. 10b), and then the wave energy propagates northeastward to North America. The anomalous subsidence in the Maritime Continent results in cyclonic circulations over South China, which also contributes to the wave energy concentration to North America (Fig. 10e). (d) Lag -6

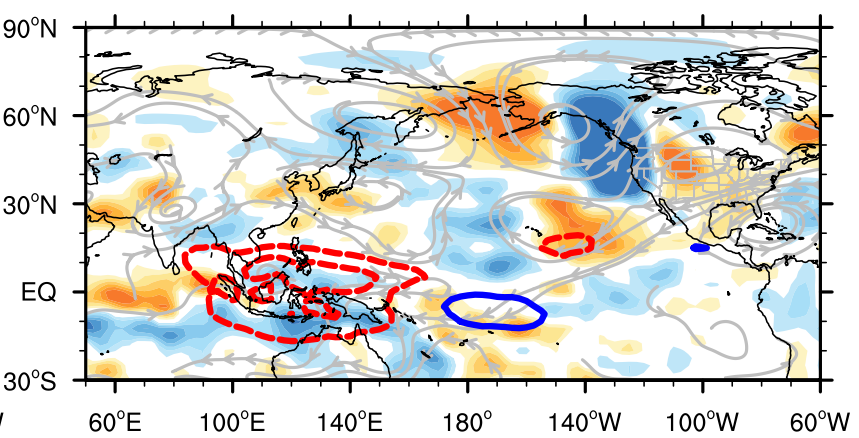

(e) Lag -3

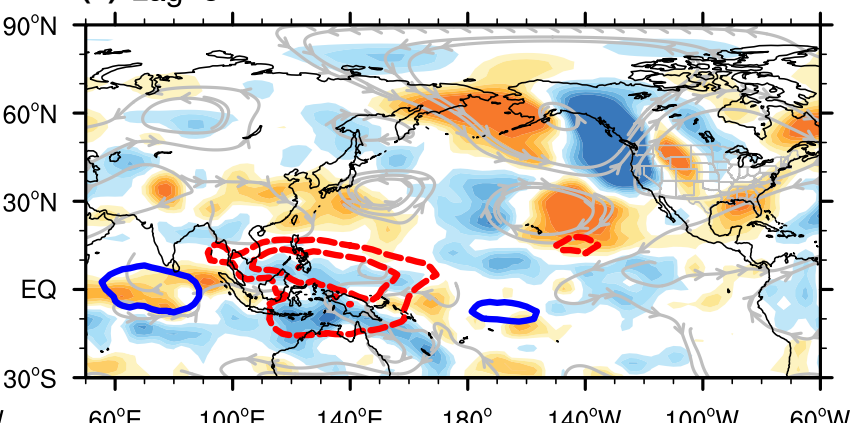

(f) Lag 0

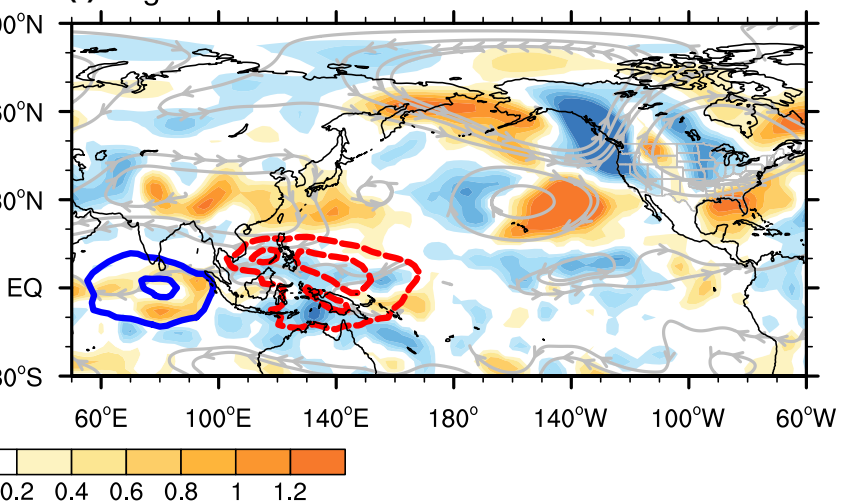

with the normalized PC1. Red dashed contours denote enhanced MJO convection (negative OLR anomaly) and blue solid contours represent suppressed MJO convection (positive OLR anomaly)

The lagged composites of the 20-100-day filtered streamlines and vertical velocity at $500 \mathrm{hPa}$ associated with the normalized PC2 are shown in Fig. 11. The atmospheric circulation in the middle troposphere is consistent with that in the upper troposphere, indicating a quasi-barotropic structure. As divergence occurs between the cyclonic center over the eastern CONUS and the anticyclonic center over the western CONUS, an anomalous center of ascending motion occurs over the CONUS on Lag day - 15 (Fig. 11a). The eastward propagation of a wave train from the North Pacific to the CONUS (cf. Fig. 10) induces a dipole pattern with an anomalous ridge over the western CONUS and an anomalous trough over the eastern CONUS on Lag day 0 
(a) Lag -15

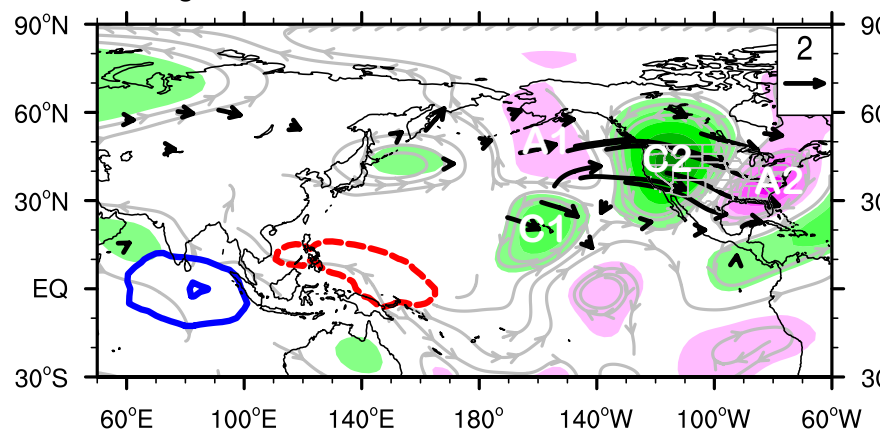

(b) Lag -12

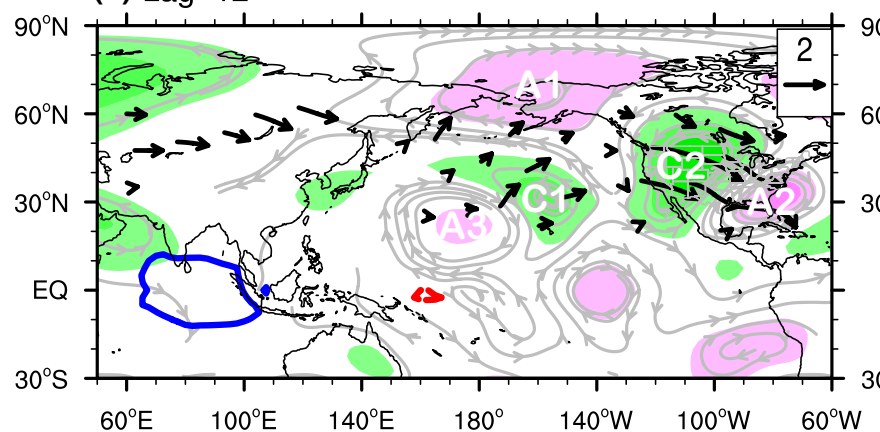

(c) Lag -9

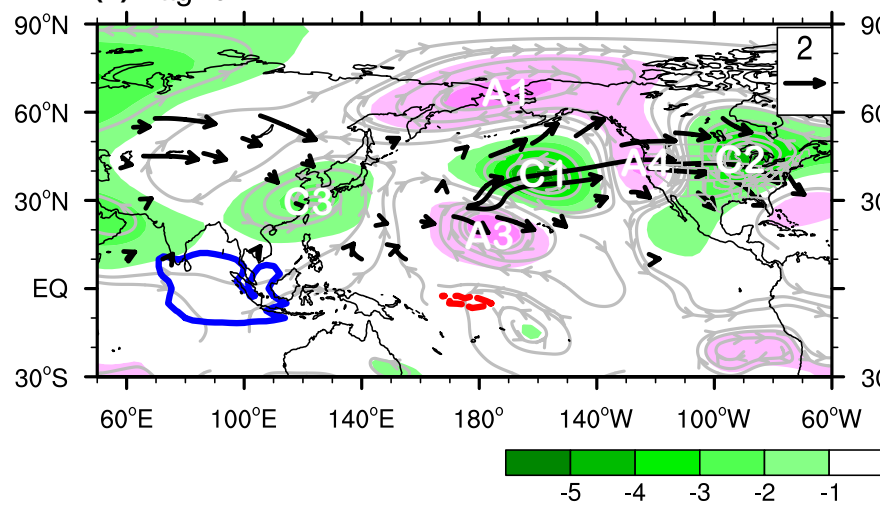

(d) Lag -6

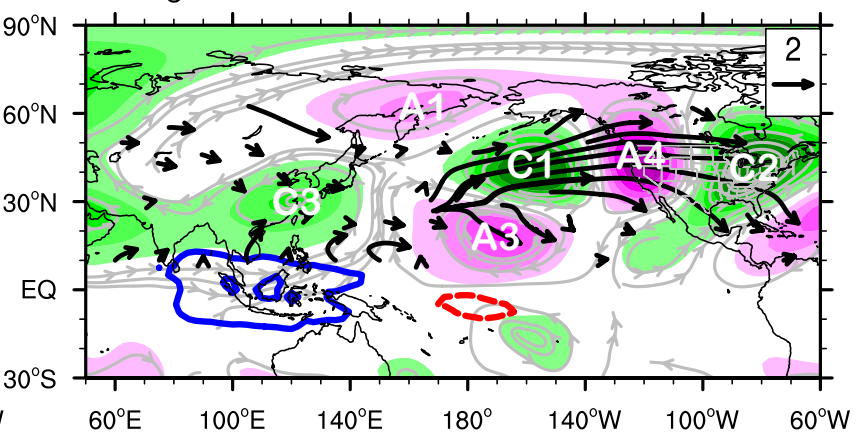

(e) Lag -3

Fig. 10 Same as Fig. 8 but for the normalized PC2

(Fig. 11f). The pressure pattern with a high over the western CONUS and a low over the eastern CONUS induces the dipole mode of the SAT (cf. Fig. 5). The anomalous ridge in the west induces mid-latitude westerlies poleward such that an anomalously warm SAT develops in the western CONUS. The anomalous downstream trough advects cold air from the Polar areas to the eastern CONUS, which leads to regional cooling.

The analyses above demonstrate that the tropical forcing induced by MJO convections substantially impacts the dominant intraseasonal SAT patterns over the CONUS through Rossby wave train propagation from the tropics to North America. To verify the lagged relationship between the monopole warming or "warm-West/cool-East" dipole pattern of the SAT over the CONUS and the MJO phases, we count the number of days when each phase of strong MJO events precedes the two leading EOF modes of the SAT. Table 1 shows the accumulated days in each MJO phase for the 112 strong cases corresponding to or prior to the day when the normalized PCs are greater than 1 STD over the CONUS with a time lag of three to one pentad. The first criterion is PC1 $>1 \mathrm{STD}$. The MJO is in phase 3 when the accumulated day peaks at Lag pentad -3 . The maxima occur in the following two pentads and on Lag day 0 during MJO phases 4,5 , and 7 . It means that enhanced MJO convection is located over the Indian Ocean three pentads before, and then the convection moves eastward to the Maritime Continent and Western Pacific. Second, when PC2 > 1STD, the accumulated day reaches its peak during phase 7, approximately 2-3 pentads before Lag day 0 . This indicates that 
(a) Lag -15

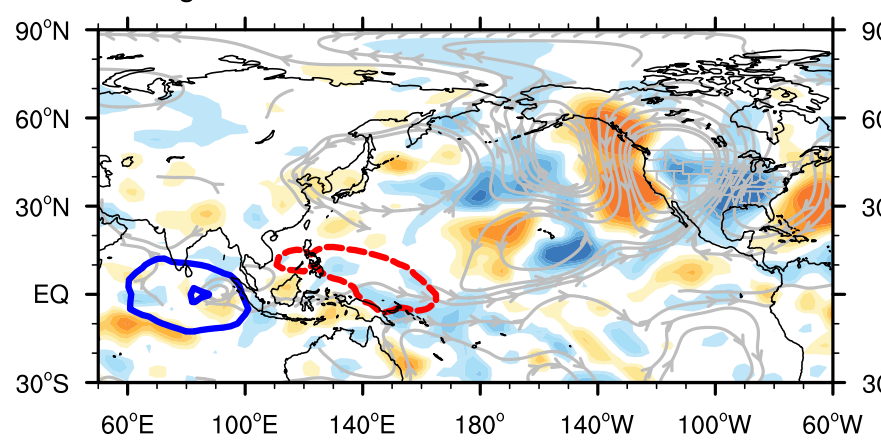

(b) Lag -12

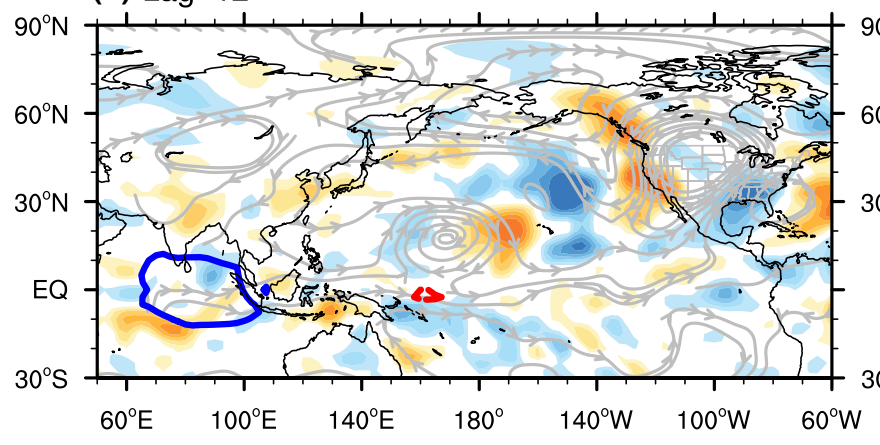

(c) Lag -9

$90^{\circ} \mathrm{N}$
$60^{\circ} \mathrm{N}$
$30^{\circ} \mathrm{N}$
$\mathrm{EQ}$
$30^{\circ} \mathrm{S}$

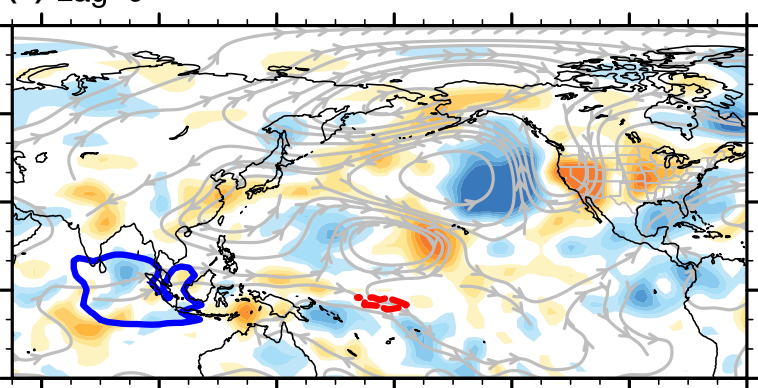

$\begin{array}{lllllll}60^{\circ} \mathrm{E} & 100^{\circ} \mathrm{E} & 140^{\circ} \mathrm{E} & 180^{\circ} & 140^{\circ} \mathrm{W} & 100^{\circ} \mathrm{W} & 60^{\circ} \mathrm{W}\end{array}$ (d) Lag -6

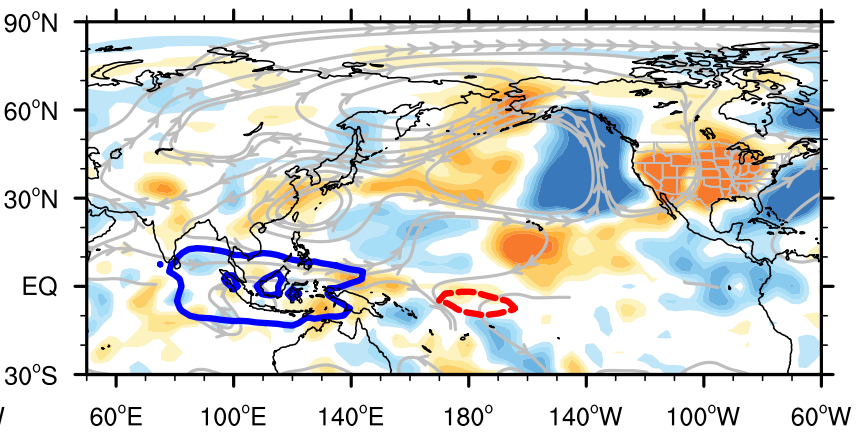

(e) Lag -3

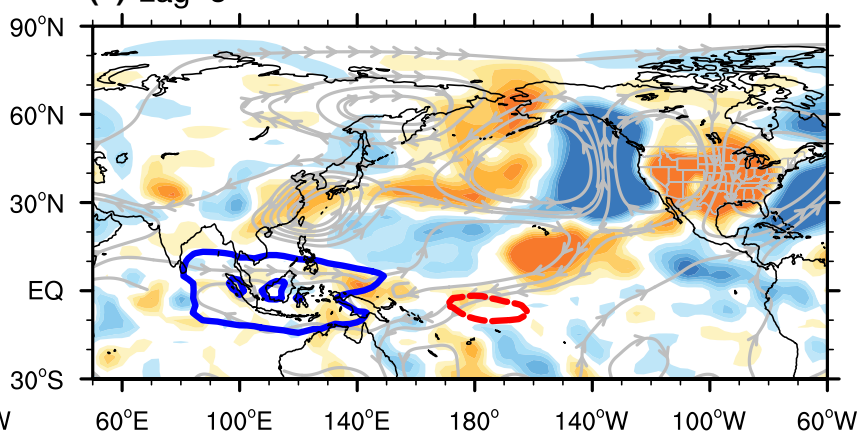

(f) Lag 0

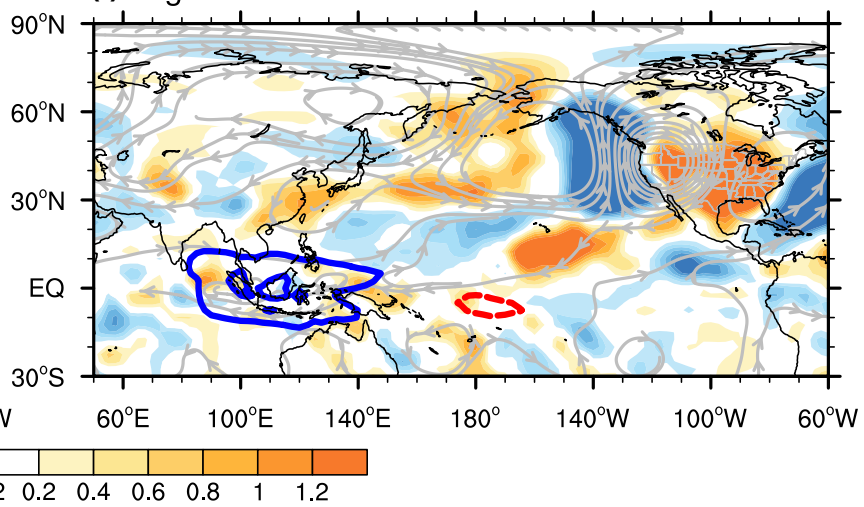

Fig. 11 Same as Fig. 9 but for the normalized PC2

Table 1 Accumulated days in each MJO phase for the 112 strong cases corresponding to or prior to the day when the normalized PCs are greater than 1 STD over the CONUS with a time lag of three to one pentad

\begin{tabular}{llrrrrrrrr}
\hline Criteria & Period & \multicolumn{1}{l}{ MJO phase } & & & & & \\
\cline { 2 - 9 } & & P1 & P2 & P3 & P4 & P5 & P6 & P7 & P8 \\
\hline PC1 > 1STD & Lag -3 pentad & 63 & 188 & $\mathbf{3 3 2}$ & 209 & 146 & 184 & 150 & 75 \\
& Lag -2 pentad & 59 & 85 & 253 & $\mathbf{2 7 6}$ & 180 & 211 & 185 & 116 \\
& Lag -1 pentad & 80 & 38 & 149 & 230 & $\mathbf{2 3 8}$ & 208 & 235 & 182 \\
& Lag 0 day & 18 & 13 & 21 & 38 & 43 & 50 & $\mathbf{5 5}$ & 38 \\
PC2 $>$ 1STD & Lag -3 pentad & 124 & 56 & 59 & 83 & 180 & 158 & $\mathbf{2 8 7}$ & 267 \\
& Lag -2 pentad & 187 & 64 & 48 & 65 & 122 & 106 & $\mathbf{3 4 6}$ & 285 \\
& Lag -1 pentad & 256 & 81 & 65 & 96 & 89 & 97 & 240 & $\mathbf{3 2 0}$ \\
& Lag 0 day & $\mathbf{6 5}$ & 21 & 21 & 19 & 15 & 19 & 34 & 61 \\
\hline
\end{tabular}

Entries in bold denote the maximum of days in MJO phase during each leading pentad and at Lag 0 day 
when the enhanced MJO convection is in the Western Pacific or Western Hemisphere and accompanied by suppressed MJO convection over the Maritime Continent (cf. Fig. 10), a warm-West/cool-East dipole mode of SAT develops over the CONUS. These results agree well with those shown in Figs. 8 and 10.

The above analyses demonstrate that enhanced MJO convective heating over the Maritime Continent during phase 4 tends to induce warm the intraseasonal SAT anomalies to develop over the entire CONUS (monopole pattern), especially the northeastern part. After two pentads, the monopole warming over the CONUS is well developed, which corresponds to the eastward propagation of the MJO.

To further verify the responses of atmospheric circulation in the mid-latitudes to different locations of MJO convections, two sensitivity experiments are performed by specifying additional three-dimensional heating over the equatorial Indian Ocean and western Pacific in the LBM, centered at the points $\left(0^{\circ}, 80^{\circ} \mathrm{E}\right)$ and $\left(0^{\circ}, 165^{\circ} \mathrm{E}\right)$, respectively. The vertical heating profile is consistent with that used to examine the direct response of global atmospheric circulation anomalies to MJO convection in the numerical study of Seo and Son (2012). The peak of heating rate is approximately $2.5 \mathrm{~K} \mathrm{day}^{-1}$ at $\sigma=0.35$ (Fig. 12a). The locations of heating (Fig. 12b, c) correspond to enhanced MJO convection during phases 3 and 7 (cf. Figs. 8, 10).

Figure 13 shows the responses of geopotential heights at $500 \mathrm{hPa}$ to the enhanced MJO convection in phases 3 and 7. The contrast results between the two experiments demonstrate that after 5 days, the heating over the equatorial Indian Ocean produces an arc-like Rossby wave propagating from the tropics to North America (Fig. 13b), whereas the heating over the equatorial western Pacific induces a canonical Rossby wave propagating from the central Pacific to North America (Fig. 13f). Such wave propagations are consistent with the composite results of the stream function and wave activity flux on day Lag -9 (Figs. 8c, 10c). After 15 days, the mid-level geopotential height over the CONUS manifests as monopole and dipole patterns as a response to the heating over the equatorial Indian Ocean and western Pacific (Fig. 13d, h). The patterns agree well with the composite results of the 500-hPa geopotential height (Figs. 4f, 5f). The experiments also indicate that the heating collocated with enhanced convections during MJO phases 3 and 7 establishes Rossby wave trains from the tropics to North America and to further induce the monopole warming pattern and the "warm-West/cool-East" dipole pattern of the SAT over the CONUS about three pentads later. Seo and Son (2012) presented that the MJO-related diabatic heating over the Indian and western Pacific Oceans can directly affect the global circulation by using a primitive equation model, which is consistent with our numerical results.

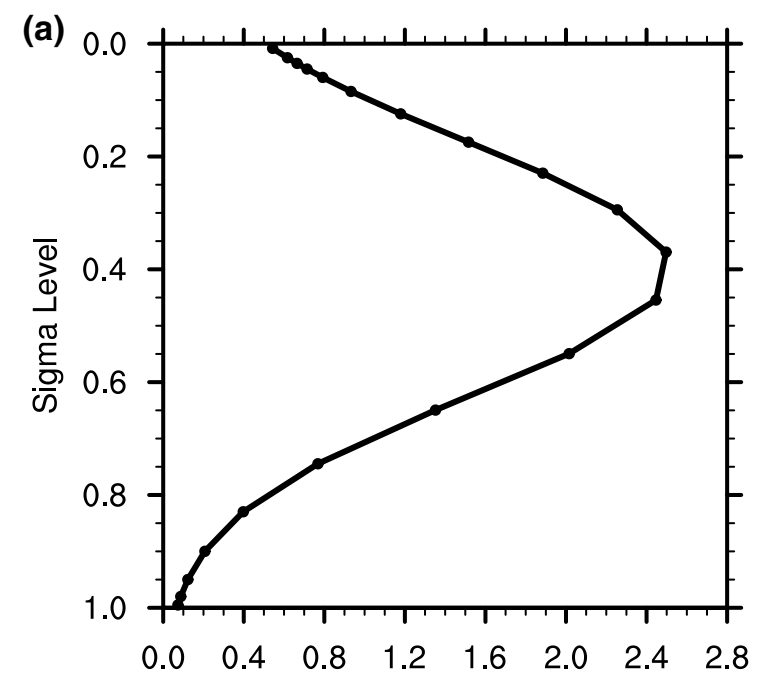

(b)

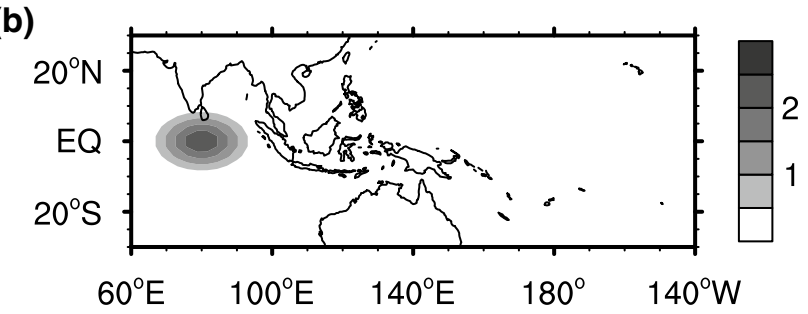

(c)

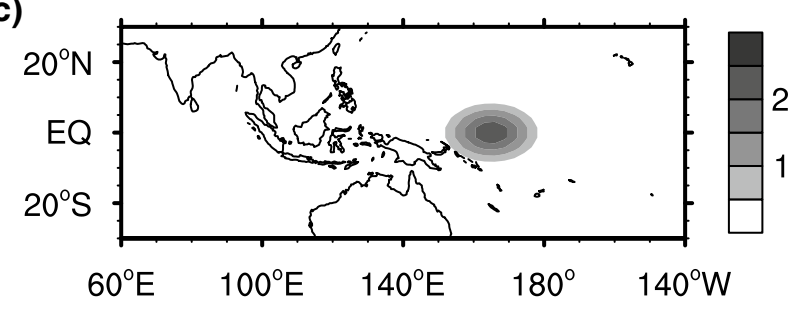

Fig. 12 a Vertical profile and horizontal distribution of the additional heating $\left(\mathrm{K} \mathrm{day}^{-1}\right)$ centered at $\mathbf{b}$ the equatorial Indian Ocean $\left(0^{\circ}\right.$, $\left.80^{\circ} \mathrm{E}\right)$ and $\mathbf{c}$ the equatorial western Pacific $\left(0^{\circ}, 165^{\circ} \mathrm{E}\right)$ in the experiment design

\section{Summary and discussion}

The first two leading EOF modes of the winter-time intraseasonal (20-100 days) SAT over the CONUS are derived in the present study. These modes are associated with mid-latitude atmospheric circulation anomalies in response to tropical MJO convections through Rossby wave flux transport. Leadlag relationships are established between these modes and the tropical convections during strong MJO phases with either enhanced or suppressed convections.

The two EOFs explain $53.8 \%$ and $20.5 \%$ of the total variance in the intraseasonal SAT, respectively. The EOF1 is featured by a monopole pattern with the largest loading occurring in the central-northern CONUS, and the EOF2 shows a dipole pattern with opposing signs over 
(a) 0 day

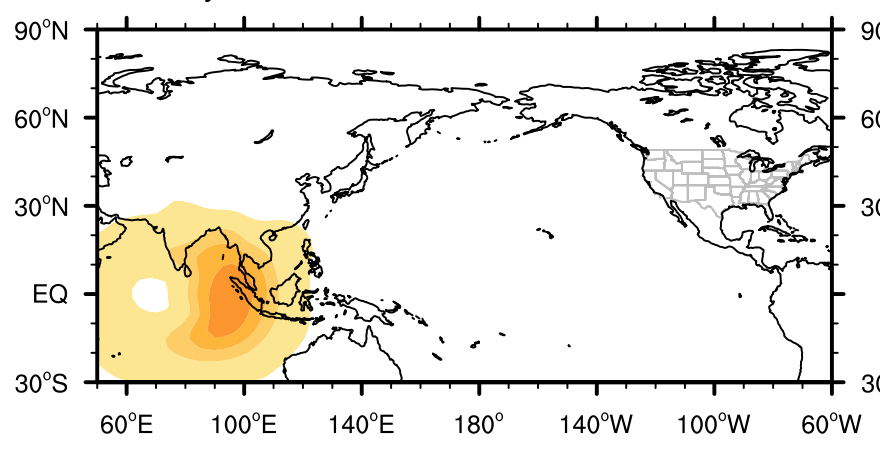

(b) +5 day

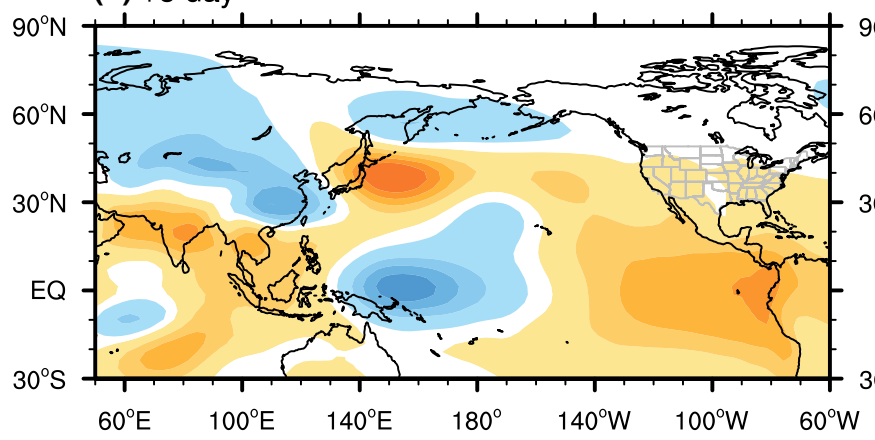

(c) +10 day

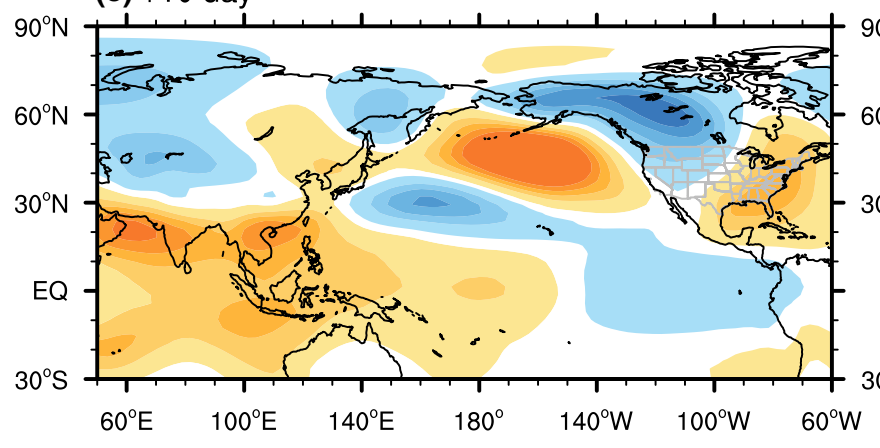

(d) +15 day

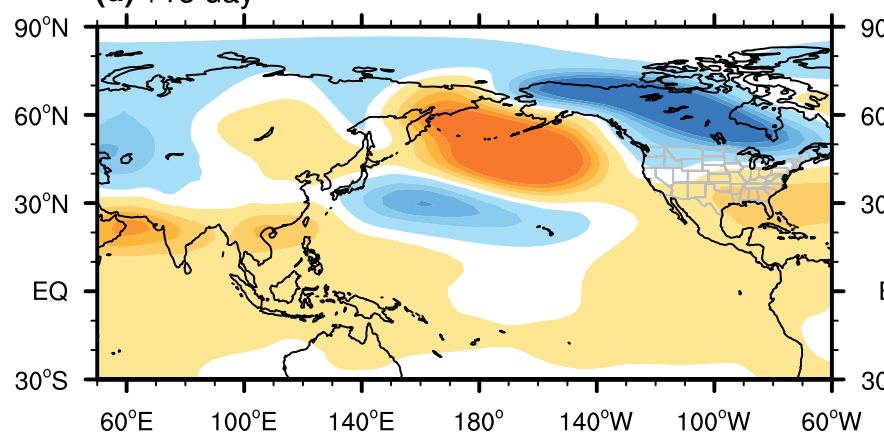

(h) +15 day

(g) +10 day (e) 0 day

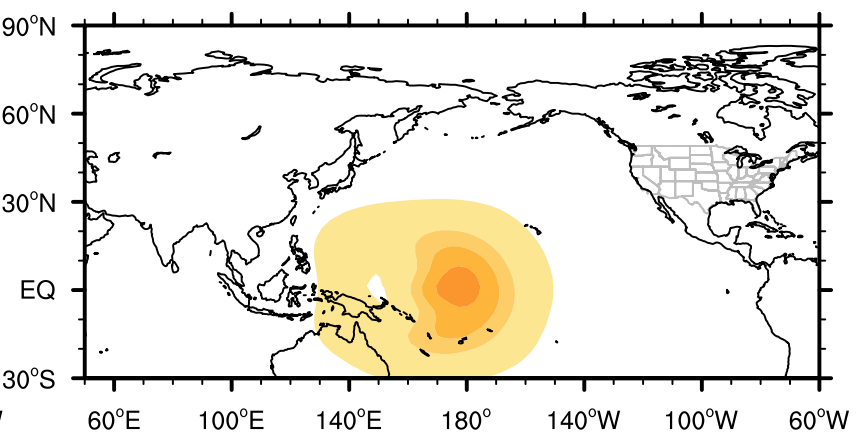

(f) +5 day
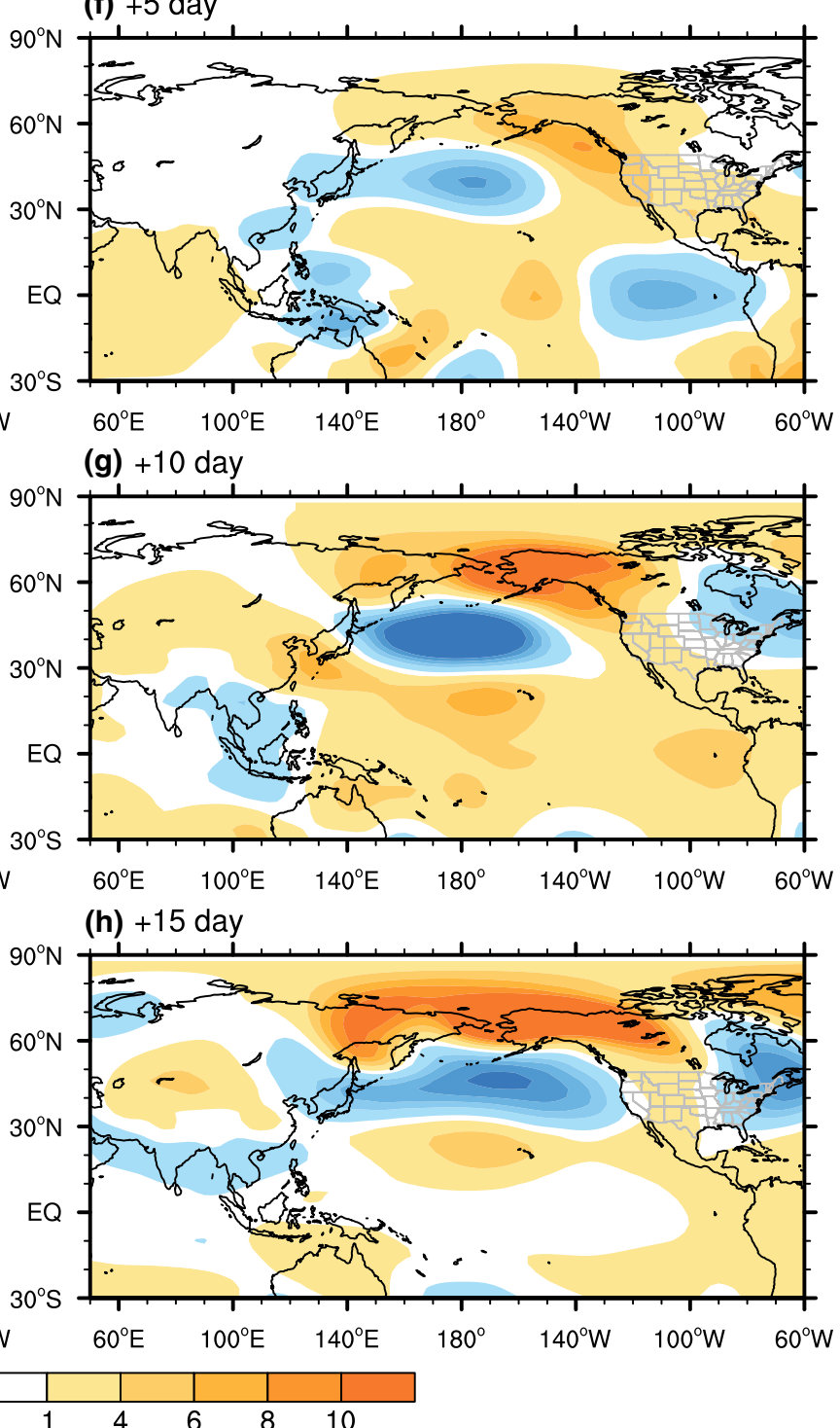

Fig. 13 Evolutions of geopotential height (gpm) at $500 \mathrm{hPa}$ since an additional heating is added over a-d the equatorial Indian Ocean and $\mathbf{e}-\mathbf{h}$ the equatorial western Pacific in LBM, respectively

the northwestern and southeastern CONUS. The principal components (PCs) of the two modes show a significant lead-lag correlation at 15 days, which is a period of transition (or reverse) from a dominant negative monopole (-EOF1) pattern to a positive dipole (EOF2) pattern. The two modes may share similar physical origins 
(a)

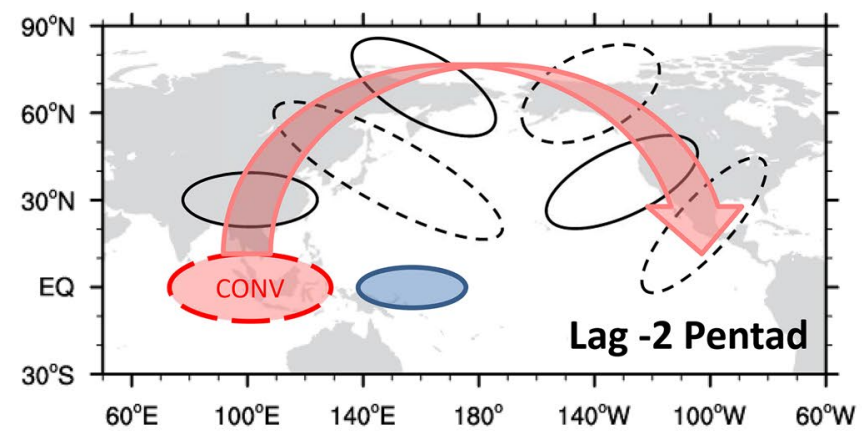

(b)

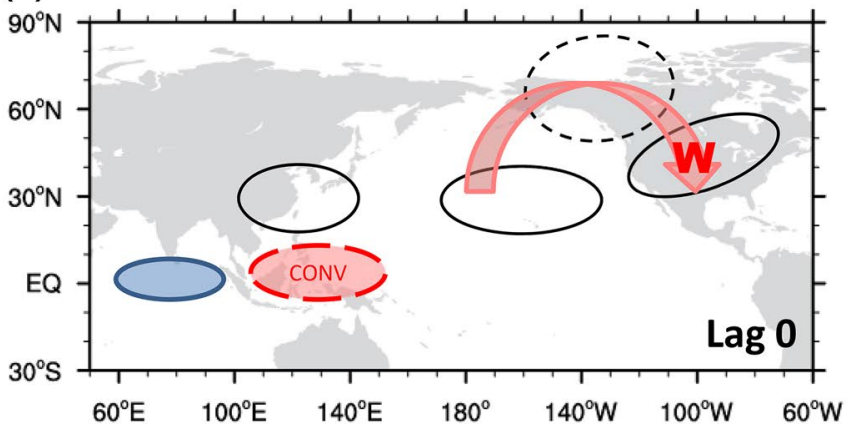

Fig. 14 Schematic diagram illustrating the mechanisms generating the two dominate modes in response to the MJO convection. Wave propagations (red arrows) triggered by enhanced (red shading) and suppressed (blue shading) MJO convections with respect to the PC1 $(\mathbf{a}, \mathbf{b})$ and PC2 (c, d) are greater than 1 STD. Note that the mono- (c)

PC2 $>1$ std

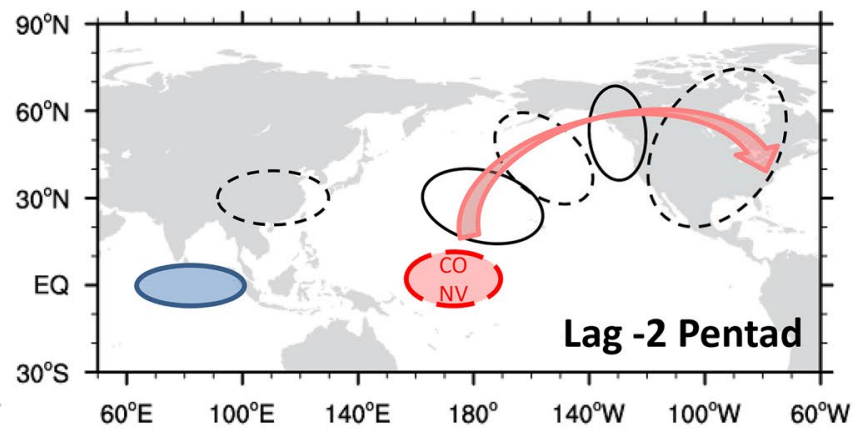

(d)

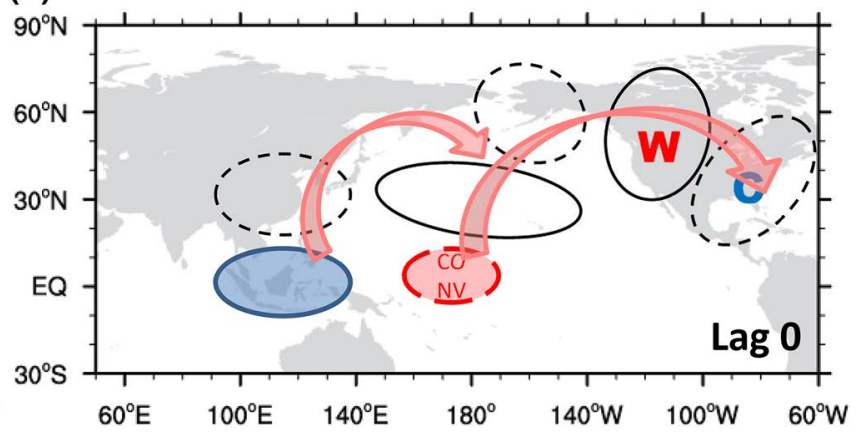

pole warming over the CONUS (b) develops 2 pentads later beginning from MJO phase 4 (a), while the "warm-West/cool-East" dipole pattern over the CONUS (d) is attributed to the enhanced convection over the Western Pacific during MJO phase 7 (c) 2 pentads earlier

from the tropics to North America. During the development of a uniform warming over the CONUS, enhanced MJO convection first develops in the eastern Indian Ocean and suppressed MJO convection occurs over the equatorial Western Pacific (Fig. 8a). Then, the evolution of the Rossby wave fluxes indicates an arc-like Rossby wave propagating from the tropics to North America, when the enhanced convection is located over the Maritime Continent in MJO phase 4 (Fig. 8c). Meanwhile, a dipole pattern of the intraseasonal SAT is generated with an anticyclonic center over the western CONUS and a cyclonic center over the eastern CONUS (Fig. 14a). When the enhanced MJO convection moves to the Western Pacific, a Rossby wave propagates from the central Pacific to North America. As a result, warm SAT anomalies cover the CONUS as a monopole mode (Fig. 14b). These Rossby waves agree well with those explained dynamically by Seo and Lee (2017) using GCM simulations, i.e., the longest waves at zonal wavenumber 1 originating from north of the enhanced MJO convection in the Indian Ocean form an arc-like propagation to North America. The formation of a Rossby wave in developing the latter half of uniform warming is determined by two pathways: (1) waves at zonal wavenumbers 1 and 2 feature a canonical Rossby wave 
propagating from the jet exit region in the central Pacific to North America; and (2) shorter waves are displaced downstream and emanate in the jet exit regions to North America due to the waveguide effect. Thus, the propagating Rossby waves induce the uniform warming over the CONUS with a center over the central-northern CONUS (Fig. 14b).

The "warm-West/cool-East" dipole pattern over the CONUS is also modulated by the MJO forcing but during phases different from the monopole warming (Fig. 14c, d). During the first half of this process, enhanced MJO convection occurs over the equatorial Western Pacific, although its intensity is relatively weak. North of the enhanced convection, an anticyclonic anomaly develops and induces a canonical Rossby wave propagating from the central Pacific to North America. Consequently, a giant cyclonic anomalous circulation controls nearly the entire CONUS, forming a monopole pattern of the SAT cooling (Fig. 14c). The MJO convection in the western tropical Pacific induces an extratropical response over the North Pacific and North America, which was demonstrated by the GCM simulations in Lukens et al. (2017). In the latter half of the dipole pattern, suppressed MJO convection extends to the Maritime Continent. In addition to the local response over South China, the wave flux activity indicates that the suppressed convection in the Maritime Continent contributes to the maintenance and reinforcement of the Rossby wave emanating from the central Pacific to North America. The resultant positive PNA-like teleconnection pattern induces the occurrence and development of a dipole intraseasonal SAT pattern (Fig. 14d).

Quantitative analyses focusing on the lagged relationship between the MJO phases and SAT patterns over the CONUS are concluded as follows. When the MJO is in phase 4 with enhanced convection over the Maritime Continent, a uniform warming over the CONUS is more likely to occur and reaches its peak after two pentads. In contrast, when the MJO is in phase 7 with enhanced convection over the equatorial Western Pacific, a dipole pattern of "warm-West/coolEast" is more likely to be generated and reach its maximum two pentads later.

The two EOFs are modulated by the MJO convection with two notable differences. One is that OLR anomalies (MJO convection) are stronger for the PC1 than the PC2. The other is that the peak EOF1 (monopole) mode is more likely modulated by the MJO convection propagating from the Western Hemisphere to the Indian Ocean, while the peak EOF2 (dipole) mode is more likely modulated by the MJO convection east of the date line. Such differences merit additional investigation to link the MJO convections to the intraseasonal SAT variability over the CONUS to potentially improve subseasonal predictions.

Acknowledgements This study is supported by the National Weather Service under Grant number NA15NWS4680015. Wenting Hu acknowledges the support of the National Key Basic Research Program of China (Grant no. 2015CB453202), the Key Research Program of Frontier Sciences, CAS (Grant no. QYZDY-SSW-DQC018), the National Natural Science Foundation of China (Grant no. 91637312, 41875076, 41505049, and 41775047), and the Open Project of the State Key Laboratory of Water Resources and Hydropower Engineering Science (2016SWG01).

Open Access This article is distributed under the terms of the Creative Commons Attribution 4.0 International License (http://creativeco mmons.org/licenses/by/4.0/), which permits unrestricted use, distribution, and reproduction in any medium, provided you give appropriate credit to the original author(s) and the source, provide a link to the Creative Commons license, and indicate if changes were made.

\section{References}

Annamalai H, Sperber KR (2005) Regional heat sources and the active and break phases of boreal summer intraseasonal (30-50 day) variability. J Atmos Sci 62:2726-2748. https://doi.org/10.1175/ JAS3504.1

Blackmon ML, Lee Y-H, Wallace JM, Hsu H-H (1984) Time variation of 500-mb height fluctuations with long, intermediate and short time scales. J Atmos Sci 41:981-991

Cui YF, Duan AM, Liu YM, Wu GX (2015) Interannual variability of the spring atmospheric heat source over the Tibetan Plateau forced by the North Atlantic SSTA. Clim Dyn 45:1617-1634. https://doi. org/10.1007/s00382-014-2417-9

Duchon CE (1979) Lanczos filtering in one and two dimensions. J Appl Meteorol 18:1016-1022

Ham Y-G, Kug J-S, Kang I-S (2007) Role of moist energy advection in formulating anomalous Walker circulation associated with El Niño. J Geophys Res 112:D24105. https://doi.org/10.1029/2007J D008744

Hendon HH, Liebmann B, Newman M, Glick JD (2000) Medium-range forecast errors associated with active episodes of the MaddenJulian oscillation. Mon Weather Rev 128:69-86

Higgins RW, Shi W (2001) Intercomparison of the principal modes of interannual and intraseasonal variability of the North American Monsoon System. J Clim 14:403-417

Higgins RW, Schemm JK, Shi W, Leetmaa A (2000) Extreme precipitation events in the western United States related to tropical forcing. J Clim 13:793-820

Jin F, Hoskins BJ (1995) The direct response to tropical heating in a baroclinic atmosphere. J Atmos Sci 52:307-319

Kalnay E, Kanamitsu M, Kistler R et al (1996) The NCEP/NCAR 40-year reanalysis project. Bull Am Meteorol Soc 77:437-472

Kanamitsu M, Ebisuzaki W, Woollen J, Yang SK, Hnilo JJ, Fiorino M, Potter GL (2002) NCEP-DOE AMIP-II Reanalysis (R-2). Bull Am Meteorol Soc 83:1631-1643

Liebmann B, Smith CA (1996) Description of a complete (Interpolated) outgoing longwave radiation dataset. Bull Am Meteorol Soc 77:1275-1277

Lin H (2015) Subseasonal variability of North American wintertime surface air temperature. Clim Dyn 45:1137-1155

Lin H, Brunet G (2009) The influence of the Madden-Julian oscillation on Canadian wintertime surface air temperature. Mon Weather Rev 137:2250-2262

Liu P (2018) MJO evolution and predictability disclosed by the RMM variant with balanced $\mathrm{MJO}$ variance in convection and zonal winds. Clim Dyn. https://doi.org/10.1007/s00382-018-4274-4 
Liu P, Zhang Q, Zhang C, Zhu Y, Khairoutdinov M, Kim H, Schumacher C, Zhang M (2016) A revised real-time multivariate MJO index. Mon Weather Rev 144:627-642

Livneh B, Bohn TJ, Pierce DS, Munoz-Ariola F, Nijssen B, Vose R, Cayan D, Brekke LD (2015) A spatially comprehensive, hydrometeorological data set for Mexico, the U.S., and southern Canada 1950-2013. Sci Data 2:150042

Lukens KE, Feldstein SB, Yoo C, Lee S (2017) The dynamics of the extratropical response to Madden-Julian Oscillation convection. Q J R Meteorol Soc 143:1095-1106

Madden RA, Julian PR (1972) Description of global-scale circulation cells in the tropics with a 40-50 day period. J Atmos Sci 29:1109-1123

Matsueda S, Takaya Y (2015) The global influence of the Madden-Julian Oscillation on extreme temperature events. J Clim 28:4141-4151

Matthews AJ, Hoskins BJ, Masutani M (2004) The global response to tropical heating in the Madden-Julian oscillation during the northern winter. Q J R Meteorol Soc 130:1991-2011

Mori M, Watanabe M (2008) The growth and triggering mechanisms of the PNA: a MJO-PNA coherence. J Meteorol Soc Jpn 86:213-236

North GR, Bell TL, Cahalan RF, Moeng FJ (1982) Sampling errors in the estimation of empirical orthogonal functions. Mon Weather Rev 110:699-706

Plumb RA (1985) On the three-dimensional propagation of stationary waves. J Atmos Sci 42:217-229

Riddle EE, Stoner MB, Johnson NC, L'Heureux ML, Collins DC, Feldstein SB (2013) The impact of the MJO on clusters of wintertime circulation anomalies over the North American region. Clim Dyn 40:1749-1766

Rodney M, Lin H, Derome J (2013) Subseasonal prediction of wintertime North American surface air temperature during strong MJO events. Mon Weather Rev 141:2897-2909

Schreck CJ III, Cordeira JM, Margolin D (2013) Which MJO events affect North American temperatures? Mon Weather Rev 141:3840-3850

Seo K, Lee H (2017) Mechanisms for a PNA-like teleconnection pattern in response to the MJO. J Atmos Sci 74:1767-1781

Seo KH, Son SW (2012) The global atmospheric circulation response to tropical diabatic heating associated with the Madden-Julian oscillation during northern winter. J Atmos Sci 69:79-96

Seo K, Lee H, Frierson D (2016) Unraveling the teleconnection mechanisms that induce wintertime temperature anomalies over the Northern Hemisphere continents in response to the MJO. J Atmos Sci 73:3557-3571
Singh D, Swain DL, Mankin JS, Horton DE, Thomas LN, Rajaratnam B, Diffenbaugh NS (2016) Recent amplification of the North American winter temperature dipole. J Geophys Res Atmos 121:9911-9928

Straub KH (2013) MJO initiation in the real-time multivariate MJO index. J Clim 26:1130-1151

Takaya K, Nakamura H (2001) A formulation of a phase independent wave-activity flux for stationary and migratory quasi-geostrophic eddies on a zonally varying basic flow. J Atmos Sci 58:608-627

Vecchi GA, Bond NA (2004) The Madden-Julian Oscillation (MJO) and northern high latitude wintertime surface air temperatures. Geophys Res Lett 31:L04104

Waliser D et al (2009) MJO simulation diagnostics. J Clim 22:3006-3030

Watanabe M, Jin FF (2003) A moist linear baroclinic model: coupled dynamical-convective response to El Niño. J Clim 16:1121-1139. https://doi.org/10.1175/1520-0442(2003)16,1121:AMLBM C.2.0.CO;2

Watanabe M, Kimoto M (2000) Atmosphere-ocean thermal coupling in the North Atlantic: a positive feedback. Q J R Meteorol Soc 126:3343-3369. https://doi.org/10.1002/qj.49712657017

Wheeler MC, Hendon HH (2004) An all-season real-time multivariate MJO index: development of an index for monitoring and prediction. Mon Weather Rev 132:1917-1932

Wolding BO, Maloney ED (2015) Objective diagnosis and the Madden-Julian Oscillation. Part I: methodology. J Clim 28:4127-4140

Yanai M, Esbensen S, Chu J (1973) Determination of bulk properties of tropical cloud clusters from large-scale heat and moisture budgets. J Atmos Sci 30:611-627

Yang S, Li T (2016) Intraseasonal variability of air temperature over the mid-high latitude Eurasia in boreal winter. Clim Dyn 47:2155-2175

Yoo C, Lee S, Feldstein S (2012) Mechanisms of Arctic surface air temperature change in response to the Madden-Julian Oscillation. J Clim 25:5777-5790

Zhang PF, Liu YM, He B (2016) Impact of East Asian summer monsoon heating on the interannual variation of the South Asian high. J Clim 29:159-173. https://doi.org/10.1175/JCLI-D-15-0118.1

Zhou S, L'Heureux M, Weaver S, Kumar A (2012) A composite study of the MJO influence on the surface air temperature and precipitation over the continental United States. Clim Dyn 38:1459-1471

Publisher's Note Springer Nature remains neutral with regard to jurisdictional claims in published maps and institutional affiliations. 